Check for updates

Cite this: RSC Adv., 2017, 7, 19039

Received 19th February 2017

Accepted 15th March 2017

DOI: $10.1039 / c 7 r a 02063 e$

rsc.li/rsc-advances

\section{Five new 2D and 3D coordination polymers based on two new multifunctional pyridyl-tricarboxylate ligands: hydrothermal syntheses, structural diversity, luminescent and magnetic properties $\dagger$}

\author{
Xiao-Yu Guo, ${ }^{a}$ Fei Zhao, ${ }^{a}$ Hou-Ting Liu, ${ }^{a}$ Yan-Qin Wang, (D) *a Zhi-Liang Liu (D) *a \\ and En-Qing Gao (iD ${ }^{b}$
}

Five coordination polymers based on pyridine-tricarboxylate ligands formulated as [Zn(HL1)] (1), $\left[\mathrm{Cd}_{2}(\mathrm{~L} 1)(\text { phen })_{2}(\mathrm{OH})\right] \cdot 2 \mathrm{H}_{2} \mathrm{O}$ (2), [Co(HL1) $\left.\left(\mathrm{H}_{2} \mathrm{O}\right)_{2}\right] \quad(3)$, $\left[\mathrm{CO}_{3}(\mathrm{L1})_{2}\left(\mathrm{H}_{2} \mathrm{O}\right)_{8}\right] \cdot 4\left(\mathrm{H}_{2} \mathrm{O}\right)$ (4) and $\left[\mathrm{Mn}_{3}(\mathrm{~L} 2)_{2}\left(4,4^{\prime}-\right.\right.$ bpy $)_{2}\left(\mathrm{H}_{2} \mathrm{O}\right)_{2}$ ] (5) $\left(\mathrm{H}_{3} \mathrm{~L} 1=4\right.$-(2,4-dicarboxylphenyl) picolinic acid, $\mathrm{H}_{3} \mathrm{~L} 2=5$-( $3^{\prime}, 5^{\prime}$-dicarboxylphenyl) nicotinic acid, phen =1,10-phenanthroline, 4,4'-bpy $=4,4^{\prime}$-bipyridine) were synthesized under hydrothermal conditions. Compound 1 exhibits a 2D distorted square-grid network based on $[\mathrm{Zn}(\mu$ $\left.\mathrm{O}_{\text {carboxylate }}(\mathrm{COO})\right]_{n}$ chains. Compound 2 displays a 2D square-grid network based on tetranuclear $\left[\mathrm{Cd}_{4}\left(\mu_{3}-\mathrm{OH}\right)_{2}\left(\mathrm{O}_{\text {carboxylate }}\right)_{2}(\mathrm{COO})_{2}\right]$ units in which $\mathrm{Cd}(\Perp)$ ions are bridged by the mixed bridges of $\left(\mu_{3}-\right.$ $\mathrm{OH})_{2}\left(\mu-\mathrm{O}_{\text {carboxylate }}\right)_{2}$. Compound 3 exhibits a $2 \mathrm{D}$ network based on $[\mathrm{Co}(\mathrm{COO})]_{n}$ chains in which $\mathrm{Co}(\Perp)$ ions are bridged by a single syn-anti carboxylate bridge ( $\mu$-COO). Compound 4 features a 3D framework based on 2D layers which are further interlinked by $\mathrm{Co}(॥)$ ions, containing $[\mathrm{Co}(\mathrm{COO})]_{n}$ chains which $\mathrm{Co}(॥)$ ions are also bridged by a single syn-anti carboxylate bridge similar with that in 3 . Compound 5 shows a 2D network based on trinuclear $\left[\mathrm{Mn}_{3}(\mathrm{COO})_{6}\left(\mathrm{H}_{2} \mathrm{O}\right)_{2}\right]$ units in which $\mathrm{Mn}(॥)$ ions are bridged by the mixed bridges of $\left(\mu-\mathrm{O}_{\text {carboxylate }}\right)(\mathrm{COO})_{2}$. These compounds have been characterized by IR spectra, TGA and powder XRD pattern. Compounds 1 and 2 exhibit intense luminescence properties in the solid state at room temperature. Magnetic studies for compounds 3-5 demonstrated that the single carboxylate bridge in 3 and 4 transmits weak antiferromagnetic interactions between Co(॥) ions while the mixed bridges of $\left(\mu-\mathrm{O}_{\text {carboxylate }}\right)(\mathrm{COO})_{2}$ transmit moderate antiferromagnetic interactions between $\mathrm{Mn}(\Perp)$ ions in 5 .

\section{Introduction}

Coordination polymers or metal-organic frameworks (MOFs) have recently attracted great attention due to their intriguing architectures and potential applications in catalysis, gas adsorption, luminescence and magnetism etc. ${ }^{1}$ However, it is usually difficult to get the accurate control of the target compounds with desired structures and properties in the selfassembling processes, because various and subtle factors can affect the result, such as the coordination geometry of the metal

${ }^{a}$ College of Chemistry and Chemical Engineering, Key Laboratory of Nanomagnetic and Functional Materials, Inner Mongolia University, Huhhot, 010021, China. E-mail: yqwang_chem@imu.edu.cn; cezlliu@imu.edu.cn; Fax: +86-471-4992147; Tel: +86471-4995414

${ }^{b}$ Shanghai Key Laboratory of Green Chemistry and Chemical Processes, College of Chemistry and Molecular Engineering, East China Normal University, Shanghai 200062, China. E-mail: eqgao@chem.ecnu.edu.cn; Fax: +86-21-62233404; Tel: +8621-62233404

$\dagger$ Electronic supplementary information (ESI) available. CCDC 1530040-1530044. For ESI and crystallographic data in CIF or other electronic format see DOI: 10.1039/c7ra02063e ions, connectivity of the organic ligands, the stoichiometric ratio of reactants, reaction conditions (solvents, temperature, $\mathrm{pH}$ values), and the presence of auxiliary ligands. ${ }^{2}$ An effective synthetic approach to obtaining new compounds with predictable structures and properties to some extent is to chose appropriate organic bridging ligands with multifunctionality and the metal centers with various coordination preferences. In this context, aromatic polycarboxylic acids including $\mathrm{N}$ heterocyclic derivative have been largely explored for the construction of MOFs for their strong and versatile coordination towards metal ions. ${ }^{3-5}$ Among them, multifunctional pyridyl-polycarboxylate acids, as rigid and versatile bridging ligands, have been studied extensively, leading to a variety of MOFs with diverse topologies and interesting properties reported by us and others. ${ }^{4,5}$ Here, we are interested in the use of two new $\pi$-conjugated pyridyl-tricarboxylate ligands, 4-(2,4dicarboxylphenyl) picolinic acid $\left(\mathrm{H}_{3} \mathrm{~L} 1\right)$, 5-(3',5'-dicarboxylphenyl) nicotinic acid $\left(\mathrm{H}_{3} \mathrm{~L} 2\right)$ (Scheme 1) which still have not been explored, on the basis of the following considerations: (i) their extreme rigidity is advantageous for the construction of porous structures and the multidentate carboxylate groups can 

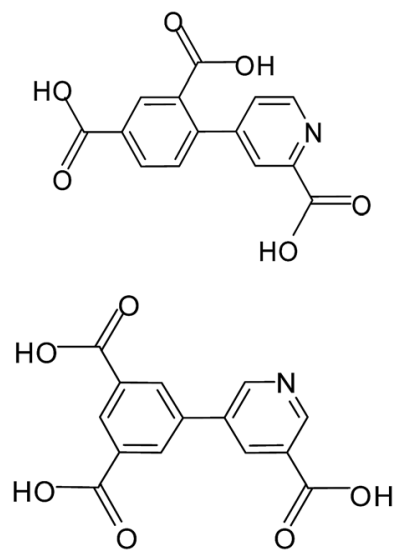

Scheme 1 4-(2,4-Dicarboxylphenyl) picolinic acid (top, $\mathrm{H}_{3} \mathrm{~L} 1$ ); 5(3',5'-dicarboxylphenyl) nicotinic acid (bottom, $\left.\mathrm{H}_{3} \mathrm{~L} 2\right)$.

strongly bind metal ions to give extended networks. (ii) The presence of phenyl ring and pyridyl ring that can rotate along the $\mathrm{C}-\mathrm{C}$ bond to give a twisted conformation, which offers possibilities of creating MOFs with new topologies. Besides, complete or partial deprotonation of such multicarboxylate ligands can also lead to the variation of coordination modes and induce structurally distinct MOFs. Apart from multifunctional carboxylate ligands, 1,10-phenanthroline (phen) and 4,4'bipyridine $\left(4,4^{\prime}\right.$-bpy) were applied as the simple N-donor auxiliary ligands to tune the structure of the coordination polymers. In this article, we present the syntheses, crystal structures, luminescent and magnetic properties of five coordination polymers, $[\mathrm{Zn}(\mathrm{HL} 1)] \quad(\mathbf{1}), \quad\left[\mathrm{Cd}_{2}(\mathrm{~L} 1)(\mathrm{phen})_{2}(\mathrm{OH})\right] \cdot 2 \mathrm{H}_{2} \mathrm{O} \quad$ (2), $\left[\mathrm{Co}(\mathrm{HL} 1)\left(\mathrm{H}_{2} \mathrm{O}\right)_{2}\right] \quad(3), \quad\left[\mathrm{Co}_{3}(\mathrm{~L} 1)_{2}\left(\mathrm{H}_{2} \mathrm{O}\right)_{8}\right] \cdot 4\left(\mathrm{H}_{2} \mathrm{O}\right) \quad(4) \quad$ and $\left[\mathrm{Mn}_{3}\left(\mathrm{H}_{3} \mathrm{~L} 2\right)_{2}\left(4,4^{\prime} \text {-bpy }\right)_{2}\left(\mathrm{H}_{2} \mathrm{O}\right)_{2}\right](5)$. Compounds 1 and 2 exhibit intense luminescence properties in the solid state at room temperature. Magnetic studies demonstrated that the single carboxylate bridge transmits weak antiferromagnetic ( $\mathrm{AF}$ ) interactions between $\mathrm{Co}(\mathrm{II})$ ions in $\mathbf{3}$ and $\mathbf{4}$ while the mixed bridges of $\left(\mu-\mathrm{O}_{\text {carboxylate }}\right)(\mathrm{COO})_{2}$ transmit moderate $\mathrm{AF}$ interactions between $\mathrm{Mn}(\mathrm{II})$ ions in $\mathbf{5}$.

\section{Experimental section}

\section{Materials and physical measurements}

The reagents and the organic ligand $\mathrm{H}_{3} \mathrm{~L} 1$ 4-(2,4-dicarboxylphenyl) picolinic acid, $\mathrm{H}_{3} \mathrm{~L} 2$ 5-(3',5'-dicarboxylphenyl) nicotinic acid, 1,10-phenanthroline (phen) and 4, $4^{\prime}$-bipyridine $\left(4,4^{\prime}\right.$ bpy) were obtained from commercial sources and used without further purification. Elemental analyses were determined on an Elementar Vario ELIII analyzer. The Fourier transform infrared (FTIR) spectra (KBr disk) were recorded in the range 500-4000 $\mathrm{cm}^{-1}$ using $\mathrm{KBr}$ pellets on a TENSOR 27 FI-IR spectrophotometer. Powder X-ray diffraction pattern (PXRD) was carried out on a EMPYREAN PANALYTICAL apparatus. The TG curve was recorded on a SDT Q600 Thermal analyzer which was performed under the $\mathrm{N}_{2}$ atmosphere and at a heating rate of $5{ }^{\circ} \mathrm{C} \min ^{-1}$ over the temperature range of $25-800{ }^{\circ} \mathrm{C}$. The luminescence spectra for the powdered solid samples were measured at room temperature on a Hitachi F-7000 fluorescence spectrophotometer. The UV-vis absorption spectra were measured with an U3900 spectrophotometer. Magnetic measurements were performed on a Quantum Design MPMS XL7 SQUID magnetometer.

[Zn(HL1)] (1). $\mathrm{Zn}\left(\mathrm{NO}_{3}\right)_{2} \cdot 6 \mathrm{H}_{2} \mathrm{O}(0.2 \mathrm{mmol}, 0.057 \mathrm{~g}), \mathrm{H}_{3} \mathrm{~L} 1$ $(0.4 \mathrm{mmol}, 0.119 \mathrm{~g})$ were dissolved in the solvent of water (10 $\mathrm{mL}$ ) and transferred to a $23 \mathrm{~mL}$ Teflon-lined autoclave. After being stirred in air for $15 \mathrm{~min}$, the mixture was heated at $160^{\circ} \mathrm{C}$ for 3 days. After cooling to room temperature at the speed of $5{ }^{\circ} \mathrm{C} \mathrm{h}^{-1}$, yellow plate crystals of 1 were collected in a $55 \%$ yield based on $\mathrm{H}_{3} \mathrm{~L} 1$. Elem anal. calcd (\%) for $\mathrm{C}_{14} \mathrm{H}_{6} \mathrm{ZnNO}_{6}$ : C, 62.37; H, 2.24; N, 5.20. Found: C, 62.52; H, 2.62; N, 5.36\%. IR bands $\left(\mathrm{KBr}, \mathrm{cm}^{-1}\right)$ : 3432s, 1597s, 1443w, 1388s, 1238w, 1071m, 1016m, $911 \mathrm{w}, 834 \mathrm{~m}, 709 \mathrm{~m}, 681 \mathrm{~m}$.

$\left[\mathrm{Cd}_{2}(\mathbf{L 1})(\text { phen })_{2}(\mathrm{OH})\right] \cdot 2 \mathrm{H}_{2} \mathrm{O}(2) . \mathrm{CdCl}_{2}(0.3 \mathrm{mmol}, 0.055 \mathrm{~g})$, $\mathrm{H}_{3} \mathrm{~L} 1(0.2 \mathrm{mmol}, 0.057 \mathrm{~g})$ and phen $(0.3 \mathrm{mmol}, 0.059 \mathrm{~g})$ were dissolved in the solvent of water $(10 \mathrm{~mL})$ and transferred to a 23 $\mathrm{mL}$ Teflon-lined autoclave, thereafter, $600 \mu \mathrm{L}$ of $1 \mathrm{~mol} \mathrm{~L}^{-1}$ $\mathrm{NaOH}$ aqueous solution was added in the mixture. After being stirred in air for $15 \mathrm{~min}$, the mixture was heated to $160{ }^{\circ} \mathrm{C}$ for 3 days. After cooling to room temperature at the speed of $10{ }^{\circ} \mathrm{C}$ $\mathrm{h}^{-1}$, colourless crystals of 2 were collected in a $25 \%$ yield based on $\mathrm{H}_{3}$ L1. Elem anal. calcd (\%) for $\mathrm{C}_{38} \mathrm{H}_{26} \mathrm{Cd}_{2} \mathrm{~N}_{5} \mathrm{O}_{9}$ : C, 49.53; $\mathrm{H}$, 2.84; N, 7.60. Found: C, 49.26; H, 2.65; N, 7.35\%. IR bands (KBr, $\left.\mathrm{cm}^{-1}\right): 3435 \mathrm{~s}, 1638 \mathrm{~s}, 1598 \mathrm{~s}, 1462 \mathrm{~m}, 1431 \mathrm{~s}, 1375 \mathrm{~s}, 1337 \mathrm{~s}, 1097 \mathrm{~m}$, $852 \mathrm{~m}, 802 \mathrm{~m}, 767 \mathrm{~s}$.

[Co(HL1) $\left.\left(\mathrm{H}_{2} \mathrm{O}\right)_{2}\right](3) . \mathrm{CoCl}_{2} \cdot 6 \mathrm{H}_{2} \mathrm{O}(0.3 \mathrm{mmol}, 0.071 \mathrm{~g})$ and $\mathrm{H}_{3} \mathrm{~L} 1(0.2 \mathrm{mmol}, 0.057 \mathrm{~g})$ were dissolved in the solvent of water $(10 \mathrm{~mL})$ and transferred to a $23 \mathrm{~mL}$ Teflon-lined autoclave, thereafter, $200 \mu \mathrm{L}$ of $1 \mathrm{~mol} \mathrm{~L}^{-1} \mathrm{NaOH}$ aqueous solution was added in the mixture. After being stirred in air for $15 \mathrm{~min}$, the mixture was heated to $160^{\circ} \mathrm{C}$ for 3 days. After cooling to room temperature at the speed of $10{ }^{\circ} \mathrm{C} \mathrm{h}^{-1}$, light red crystals of 3 were collected in a $42 \%$ yield based on $\mathrm{H}_{3} \mathrm{~L} 1$. Elem anal. calcd (\%) for $\mathrm{C}_{14} \mathrm{H}_{11} \mathrm{CoNO}_{8}$ : $\mathrm{C}, 44.23 ; \mathrm{H}, 2.92 ; \mathrm{N}, 3.68$. Found: $\mathrm{C}, 44.50$; $\mathrm{H}, 2.47$; N, 3.46\%. IR bands $\left(\mathrm{KBr}, \mathrm{cm}^{-1}\right): 3394 \mathrm{~s}, 3233 \mathrm{~s}, 1688 \mathrm{~s}$, $1624 \mathrm{~s}, 1588 \mathrm{~s}, 1434 \mathrm{~m}, 1364 \mathrm{~s}, 1301 \mathrm{~m}, 1238 \mathrm{w}, 1132 \mathrm{~m}, 1020 \mathrm{~m}$, $943 \mathrm{~m}, 844 \mathrm{~s}, 802 \mathrm{~s}, 760 \mathrm{~s}, 732 \mathrm{~s}$.

$\left[\mathrm{Co}_{3}(\mathbf{L 1})_{2}\left(\mathrm{H}_{2} \mathrm{O}\right)_{8}\right] \cdot \mathbf{4}\left(\mathrm{H}_{2} \mathbf{O}\right)(\mathbf{4}) \cdot \mathrm{CoCl}_{2} \cdot 6 \mathrm{H}_{2} \mathrm{O}(0.3 \mathrm{mmol}, 0.071 \mathrm{~g})$ and $\mathrm{H}_{3} \mathrm{~L} 1(0.2 \mathrm{mmol}, 0.057 \mathrm{~g})$ were dissolved in the solvent of water $(10 \mathrm{~mL})$ and transferred to a $23 \mathrm{~mL}$ Teflon-lined autoclave, thereafter, $600 \mu \mathrm{L}$ of $1 \mathrm{~mol} \mathrm{~L}^{-1} \mathrm{NaOH}$ aqueous solution was added in the mixture. After being stirred in air for $15 \mathrm{~min}$, the mixture was heated to $160^{\circ} \mathrm{C}$ for 3 days. After cooling to room temperature at the speed of $10^{\circ} \mathrm{C} \mathrm{h}^{-1}$, orange crystals of 4 were collected in a $12 \%$ yield based on $\mathrm{CoCl}_{2} \cdot 6 \mathrm{H}_{2} \mathrm{O}$. Elem anal. calcd (\%) for $\mathrm{C}_{28} \mathrm{H}_{36} \mathrm{Co}_{3} \mathrm{~N}_{2} \mathrm{O}_{24}$ : C, 34.98; $\mathrm{H}, 3.77$; N, 2.91. Found: C, $34.79 ; \mathrm{H}, 3.65 ; \mathrm{N}, 2.65 \%$. IR bands $\left(\mathrm{KBr}, \mathrm{cm}^{-1}\right): 3420 \mathrm{~s}, 3290 \mathrm{~s}$, $1593 \mathrm{~s}, 1553 \mathrm{~s}, 1473 \mathrm{~m}, 1430 \mathrm{~s}, 1378 \mathrm{~s}, 1362 \mathrm{~s}, 1160 \mathrm{w}, 1022 \mathrm{~m}$, $928 \mathrm{~m}, 915 \mathrm{~m}, 774 \mathrm{~m}, 725 \mathrm{~m}$.

$\left[\mathbf{M n}_{3}\left(\mathbf{H}_{3} \mathbf{L} 2\right)_{2}\left(\mathbf{4}, \mathbf{4}^{\prime}-\mathbf{b p y}\right)_{2}\left(\mathbf{H}_{2} \mathbf{O}\right)_{2}\right](5) . \mathrm{MnCl}_{2} \cdot 4 \mathrm{H}_{2} \mathrm{O}(0.3 \mathrm{mmol}$, $0.059 \mathrm{~g}), \mathrm{H}_{3} \mathrm{~L} 2(0.2 \mathrm{mmol}, 0.057 \mathrm{~g})$ and $4,4^{\prime}$-bpy $(0.3 \mathrm{mmol}, 0.047$ $\mathrm{g})$ were dissolved in the solvent of water $(10 \mathrm{~mL})$ and transferred to a $23 \mathrm{~mL}$ Teflon-lined autoclave, thereafter, $600 \mu \mathrm{L}$ of $1 \mathrm{~mol}$ $\mathrm{L}^{-1} \mathrm{NaOH}$ aqueous solution was added in the mixture. After being stirred in air for $15 \mathrm{~min}$, the mixture was heated to $160{ }^{\circ} \mathrm{C}$ 
for 3 days. After cooling to room temperature at the speed of $10{ }^{\circ} \mathrm{C} \mathrm{h}^{-1}$, light yellow crystals of 5 were collected in a $25 \%$ yield based on $\mathrm{H}_{3} \mathrm{~L} 2$. Elem anal. calcd (\%) for $\mathrm{C}_{48} \mathrm{H}_{32} \mathrm{Mn}_{3} \mathrm{~N}_{6} \mathrm{O}_{14}: \mathrm{C}$, 53.30; H, 2.98; N, 7.77. Found: C, 53.10; H, 2.78; N, 7.54\%. IR bands $\left(\mathrm{KBr}, \mathrm{cm}^{-1}\right): 3432 \mathrm{~s}, 1629 \mathrm{~s}, 1569 \mathrm{~m}, 1496 \mathrm{~m}, 1447 \mathrm{~m}$, $1416 \mathrm{~m}, 1382 \mathrm{~s}, 1227 \mathrm{~m}, 1120 \mathrm{~m}, 1002 \mathrm{w}, 901 \mathrm{~m}, 801 \mathrm{~m}, 786 \mathrm{~m}$.

\section{Crystal data collection and refinement}

Diffraction intensity data were collected at $293 \mathrm{~K}$ on a Bruker APEX II diffractometer equipped with a CCD area detector and graphite-monochromated $\mathrm{Cu} \mathrm{K} \alpha$ radiation $(\lambda=1.54184 \AA)$ for compounds 1, 2 and 5; graphite-monochromated Mo K $\alpha$ radiation $(\lambda=0.71073 \AA)$ for compounds 3 and 4. Empirical absorption corrections were applied using the SADABS program. ${ }^{6}$ The structures were solved by the direct method and refined by the full-matrix least-squares method on $F^{2}$, with all non-hydrogen atoms refined with anisotropic thermal parameters. ${ }^{7}$ All the hydrogen atoms attached to carbon atoms were placed in calculated positions and refined using the riding model. The hydrogens attached to water molecules were located from the difference Fourier maps and refined isotropically. Crystallographic data for 1-5 have been deposited at the Cambridge Crystallographic Data Center with the deposition numbers of CCDC 1530040-1530044: 1 (1530042), 2 (1530040), 3 (1530043), 4 (1530044) and 5 (1530041). $\dagger$ A summary of the crystallographic data, data collection, and refinement parameters for compounds 1-5 are provided in Table 1 . The selected bond lengths and angles are given in Tables S1-S5. $\dagger$

\section{Results and discussion}

\section{Synthesis and IR spectral aspects}

To explore the $\mathrm{H}_{3} \mathrm{~L} 1$ and $\mathrm{H}_{3} \mathrm{~L} 2$ as ligands toward the selfassembly with metal(II) (Zn, Cd, Mn, Co) to construct coordination polymers, we have tried a lot of hydrothermal reactions by applying different metal(II) salts with $\mathrm{H}_{3} \mathrm{~L} 1$ or $\mathrm{H}_{3} \mathrm{~L} 2$ in the absence or presence of several common auxiliary ligands or potential linkers, such as 1,10-phenanthroline, 4,4'-bipyridine and 4,4'-biphenyldicarboxylic acid and so on. Compound 1 was obtained by hydrothermal reactions applying a mixture of the $\mathrm{Zn}\left(\mathrm{NO}_{3}\right)_{2} \cdot 6 \mathrm{H}_{2} \mathrm{O}$ in water with $\mathrm{H}_{3} \mathrm{~L} 1$ in a $1: 2$ molar ratio. Compound 2 was synthesized in a similar way but by using a mixture of $\mathrm{CdCl}_{2}$, with $\mathrm{H}_{3} \mathrm{~L} 1$, phen, and water solution of $\mathrm{NaOH}$ as a base in a 3000:2000:3000:6 molar ratio. Compounds 3 and 4 were synthesized by very similar way by using a mixture of $\mathrm{CoCl}_{2} \cdot 6 \mathrm{H}_{2} \mathrm{O}$, with $\mathrm{H}_{3} \mathrm{~L} 1$ and water solution of $\mathrm{NaOH}$ as a base except for the different numbers of microliter for the same concentration of $\mathrm{NaOH}$ water solution $(1 \mathrm{M})$, and $\mathrm{CoCl}_{2} \cdot 6 \mathrm{H}_{2} \mathrm{O}, \mathrm{H}_{3} \mathrm{~L} 1$ and $\mathrm{NaOH}$ are in a $3000: 2000: 2$ and 3000 : 2000: 6 molar ratios, respectively for 3 and 4. Compound 5 was obtained in a similar way by using $\mathrm{MnCl}_{2} \cdot 4 \mathrm{H}_{2} \mathrm{O}$, with $\mathrm{H}_{3} \mathrm{~L} 2,4,4^{\prime}$-bpy and $\mathrm{NaOH}$ water solution in a molar ratio of $3000: 2000: 3000: 6$.

The IR spectra of 1-5 show broad absorption bands in the range of 3409 to $3433 \mathrm{~cm}^{-1}$, respectively, attributable to the $\nu(\mathrm{O}-$ H) vibration of water molecules or hydroxyl (Fig. S1, ESI $\dagger$ ). The asymmetric and symmetric stretching vibrations of carboxylate are observed in the range of 1593-1629 and $1362-1388 \mathrm{~cm}^{-1}$, respectively.

\section{Description of the structures}

Crystal structure of 1 . Compound $\mathbf{1}$ crystallizes in the orthorhombic space group $\mathrm{Pca}_{(1)}$ and exhibits a $2 \mathrm{D}$ framework. The asymmetric unit contains one $\mathrm{Zn}$ (II) ion, one $\mathrm{HL}^{2-}$ ligand with one protonated carboxyl group and two deprotonated carboxyl groups. The coordination environment of the $\mathrm{Zn}$ (II) ion is shown in Fig. 1a. The unique $\mathrm{Zn} 1$ ion is five-coordinated in a rectangular pyramid coordination geometry, ligated by one nitrogen atoms and four oxygen atoms from four different $\mathrm{HL}^{2-}$ ligands with $\mathrm{Zn}-\mathrm{N} / \mathrm{O}$ distances in the range of 1.992(5)2.118(6) $\AA$, all the $\mathrm{Zn}-\mathrm{O}$ and $\mathrm{Zn}-\mathrm{N}$ distances in 1 are comparable to these in other reported $\mathrm{Zn}$ (II) compounds based on the

Table 1 Crystallographic data and structure refinement results for compounds 1-5

\begin{tabular}{|c|c|c|c|c|c|}
\hline Compound & 1 & 2 & 3 & 4 & 5 \\
\hline Empirical formula & $\mathrm{C}_{14} \mathrm{H}_{6} \mathrm{ZnNO}_{6}$ & $\mathrm{C}_{38} \mathrm{H}_{26} \mathrm{Cd}_{2} \mathrm{~N}_{5} \mathrm{O}_{9}$ & $\mathrm{C}_{14} \mathrm{H}_{11} \mathrm{CoNO}_{8}$ & $\mathrm{C}_{28} \mathrm{H}_{36} \mathrm{Co}_{3} \mathrm{~N}_{2} \mathrm{O}_{24}$ & $\mathrm{C}_{48} \mathrm{H}_{32} \mathrm{Mn}_{3} \mathrm{~N}_{6} \mathrm{O}_{14}$ \\
\hline Formula weight & 350.58 & 922.45 & 380.17 & 961.38 & 1081.62 \\
\hline Crystal system & Orthorhombic & Triclinic & Monoclinic & Triclinic & Triclinic \\
\hline Space group & $\operatorname{Pca2}_{(1)}$ & $P \overline{1}$ & $P 2_{(1)} / c$ & $P \overline{1}$ & $P \overline{1}$ \\
\hline$a, \AA$ & $15.7203(10)$ & $11.8521(11)$ & $18.480(2)$ & $7.1966(5)$ & $9.6330(10)$ \\
\hline$b, \AA$ & $13.1516(9)$ & $12.2200(12)$ & $9.4446(9)$ & $10.3116(6)$ & $10.6019(9)$ \\
\hline$c, \AA$ & $6.1682(4)$ & $14.6694(15)$ & $8.0006(7)$ & $12.2101(8)$ & $11.2826(10)$ \\
\hline$\alpha,^{\circ}$ & 90 & $68.971(9)$ & 90 & $102.745(2)$ & $96.503(7)$ \\
\hline$\beta, \circ$ & 90 & $68.595(9)$ & $99.263(3)$ & $101.788(2)$ & $104.988(8)$ \\
\hline$\gamma, \circ$ & 90 & $61.417(10)$ & 90 & $92.055(2)$ & $104.111(8)$ \\
\hline$V, \AA^{3}$ & $1275.26(14)$ & $1692.3(3)$ & $1378.2(2)$ & $862.02(10)$ & $1060.19(17)$ \\
\hline$Z$ & 4 & 2 & 4 & 1 & 1 \\
\hline$\rho_{\text {calcd }}, \mathrm{g} \mathrm{cm}^{-3}$ & 1.826 & 1.810 & 1.832 & 1.852 & 1.694 \\
\hline$\mu, \mathrm{mm}^{-1}$ & 2.996 & 1.324 & 1.294 & 1.531 & 7.869 \\
\hline Unique reflections & 1513 & 6091 & 2481 & 4319 & 3784 \\
\hline$R_{\text {int }}$ & 0.0434 & 0.0674 & 0.0240 & 0.0240 & 0.0598 \\
\hline$S$ on $F^{2}$ & 1.083 & 1.035 & 1.100 & 1.068 & 1.025 \\
\hline$R_{1}, \mathrm{w} R_{2}[I>2 \sigma(I)]$ & $0.0481,0.1165$ & $0.0546,0.0973$ & $0.0240,0.0620$ & $0.0254,0.0611$ & $0.0559,0.1220$ \\
\hline$R_{1}, \mathrm{w} R_{2}$ (all data) & $0.0625,0.1318$ & $0.0891,0.1248$ & $0.0261,0.0630$ & $0.0291,0.0625$ & $0.0862,0.1405$ \\
\hline
\end{tabular}




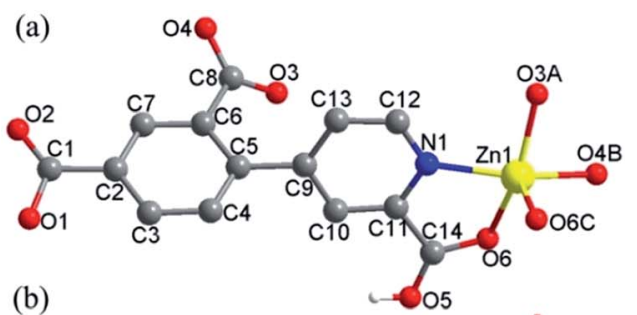

(b)
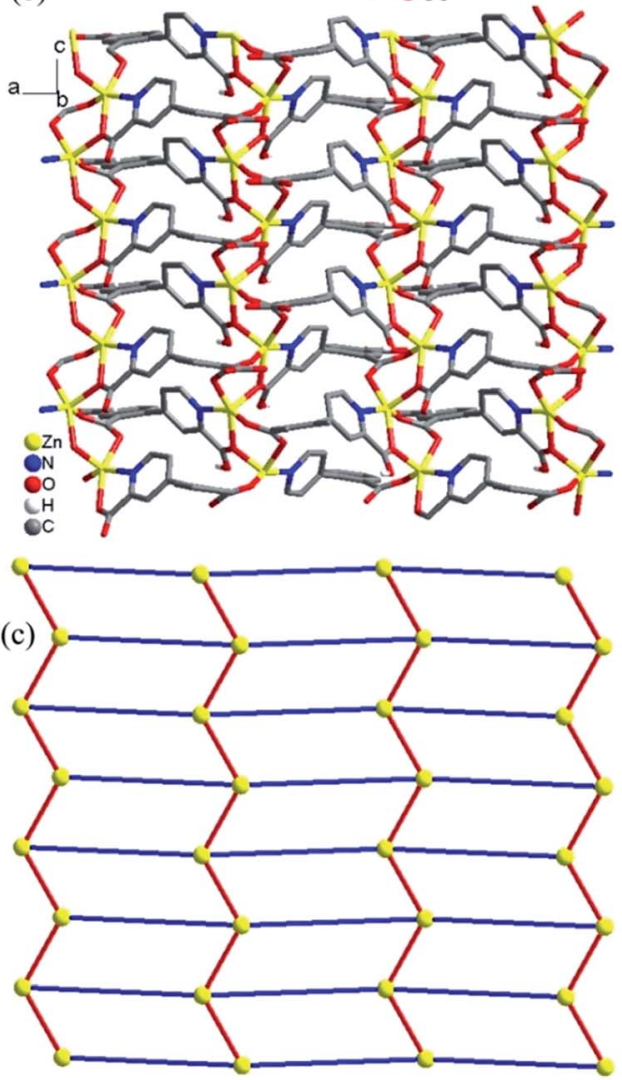

Fig. 1 (a) Local coordination environment of the $\mathrm{Zn}^{2+}$ center in 1. Symmetry codes: (A) $2-x, 1-y, 0.5+z$; (B) $0.5+x, 1-y, z$; (C) $2.5-x$, $y, 0.5+z$. (b) View of the 2D layer of 1 . (c) View of the topological net of 1 .

similar pyridine-tricarboxylate ligands. ${ }^{5 f-\boldsymbol{h}}$ The $\mathrm{HL}^{2-}$ ligand contains a bridging bidentate carboxylate group $\left(\mu_{2}-\eta^{1}: \eta^{1}-\right.$ bridging mode), a tridentate picolinic acid which the carboxylate group adopts $\mu_{2}-\eta^{1}$ bridging mode and the nitrogen atom (N1) is involved in the coordination, and a noncoordinated carboxylate group (mode I, Scheme 2). The dihedral angle between the pyridyl and phenol rings in the $\mathrm{HL}^{2-}$ is $67.2^{\circ}$.

Adjacent $\mathrm{Zn}$ (II) ions are bridged by mixed bridges of ( $\mu$ $\left.\mathrm{O}_{\text {carboxylate }}\right)(\mathrm{COO})$ into $1 \mathrm{D}$ zigzag chains along the $b$ direction with $\mathrm{Zn} \cdots \mathrm{Zn}$ distances $3.519(2) \AA$ A. Each chains bridged by carboxylate groups are interlinked by $\mathrm{HL}^{2-}$ ligands act as $\mu_{3}$ bridge into 2D layers along the $a c$ plane (Fig. 1b). The interchain $\mathrm{Zn} \cdots \mathrm{Zn}$ distances within the layer is in the range of 7.099(1)10.183(1) A. Topologically, $\mathrm{Zn}$ (II) ions and ligands can be considered as 4-connected nodes and linkers respectively, thus, the whole structure can be simplified as a $2 \mathrm{D}$ distorted squaregrid layers (Fig. 1c).
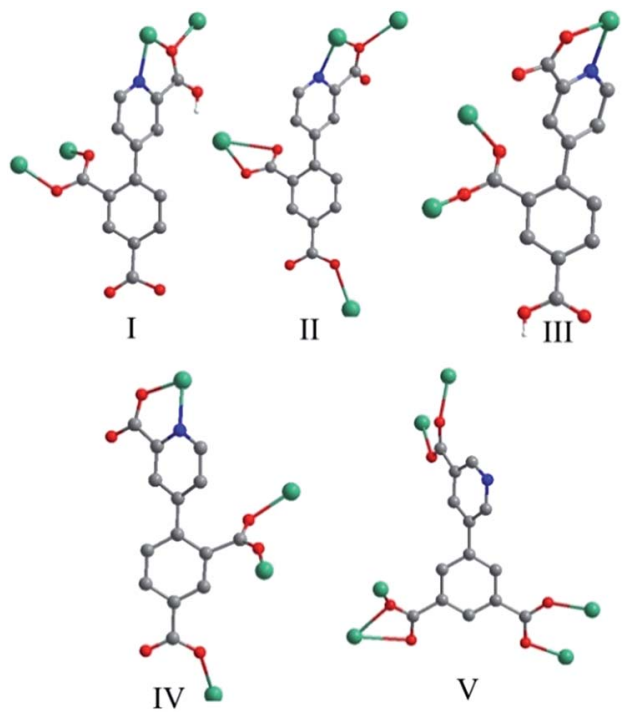

Scheme 2 Coordination modes of $\mathrm{H}_{3} \mathrm{~L} 1$ and $\mathrm{H}_{3} \mathrm{~L} 2$ in compounds 1-5.

Crystal structure of 2. This compound is also composed of 2D layers, but the layers are based on tetranuclear clusters rather than chains as that in $\mathbf{1}$. The relevant bond parameters are summarized in Table S2. $\dagger$ As shown in Fig. 2a, the tetranuclear cluster contains a centrosymmetric $\left[\mathrm{Cd}_{4}(\mathrm{OH})_{2}\right]^{6+}$ core, in which four $\mathrm{Cd}$ (II) atoms are linked by two equivalent $\mu_{3}-\mathrm{OH}$ bridges to form a planar parallelogram. The geometry can be described as two coplanar and edge-sharing $\mathrm{Cd}_{3}$ triangles that share the edge defined by two centrosymmetry-related and doubly hydroxo-bridged Cd1 atoms, with Cd1 ‥Cd1A 3.431(1) $\AA$. The $\mathrm{M}-\mathrm{O}-\mathrm{M}$ angles around the $\mu_{3}-\mathrm{OH}$ (O9) range from 98.06(2) to $140.83(2)^{\circ}$. The sum of the $\mathrm{Cd}-\mathrm{O}-\mathrm{Cd}$ angles $344.39^{\circ}$ around each $\mu_{3}-\mathrm{OH}$ is in good agreement with the tetrahedral environment of the oxygen atom, and the oxygen atom is placed above and below the $\mathrm{Cd}_{4}$ plane by $0.49 \AA$. These define a rather flat pyramidal shape for the $\mathrm{Cd}_{3} \mathrm{O}$ moiety. The tetranuclear $\left[\mathrm{Cd}_{4}\left(\mu_{3}-\mathrm{OH}\right)_{2}\right]^{6+}$ core is reinforced by two oxygen atom bridges from two carboxylate groups of two different $\mathrm{L}^{3}{ }^{3}$-ligands. There are two different bridging fashions between $\mathrm{Cd} 1$ and $\mathrm{Cd} 2$ sites. One is the double-bridging motif that contains a $\mu_{3}$-hydroxo (O9) and a carboxylate oxygen atom (O4), with $\mathrm{Cd} 1 \cdots \mathrm{Cd} 2$ $3.572(8) \AA$; the other is the single-bridging motif of the $\mu_{3}$ hydroxo (O9), with longer $\mathrm{Cd} 2 \cdots \mathrm{Cd} 1 \mathrm{~A}$ distances of $4.253(9) \AA$. The resulting $\left[\mathrm{Cd}_{4}\left(\mu_{3}-\mathrm{OH}\right)_{2}(\mathrm{O})_{2}\right]$ cluster is often observed in some complexes with different central metal ions and very similar bridges. ${ }^{8}$

The asymmetric unit contains two Cd(II) ions, one $\mathrm{L1}^{3-}$ ligand, two 1,10-phen molecules, one hydroxyl group and two lattice water molecules. The $\mathrm{Cd} 1$ ion is ligated by two nitrogen atoms (N1 and N2) from one chelating phen, two carboxylate oxygen atoms (O2 and $\mathrm{O} 4)$ from two $\mathrm{L}^{3-}$ ligands and two hydroxyl oxygen atoms (O9 and O9A) in a distorted octahedral $\left[\mathrm{N}_{2} \mathrm{O}_{4}\right]$ coordination geometry with $\mathrm{Cd}-\mathrm{N}$ bond lengths ranging from $2.325(6)$ to $2.405(5) \AA$, Cd-O bond lengths ranging from 2.251(5) to 2.342(4) $\mathrm{A}$, all the $\mathrm{Cd}-\mathrm{O}$ and $\mathrm{Cd}-\mathrm{N}$ distances in 2 are comparable to these in other reported $\mathrm{Cd}(\mathrm{II})$ compounds based 

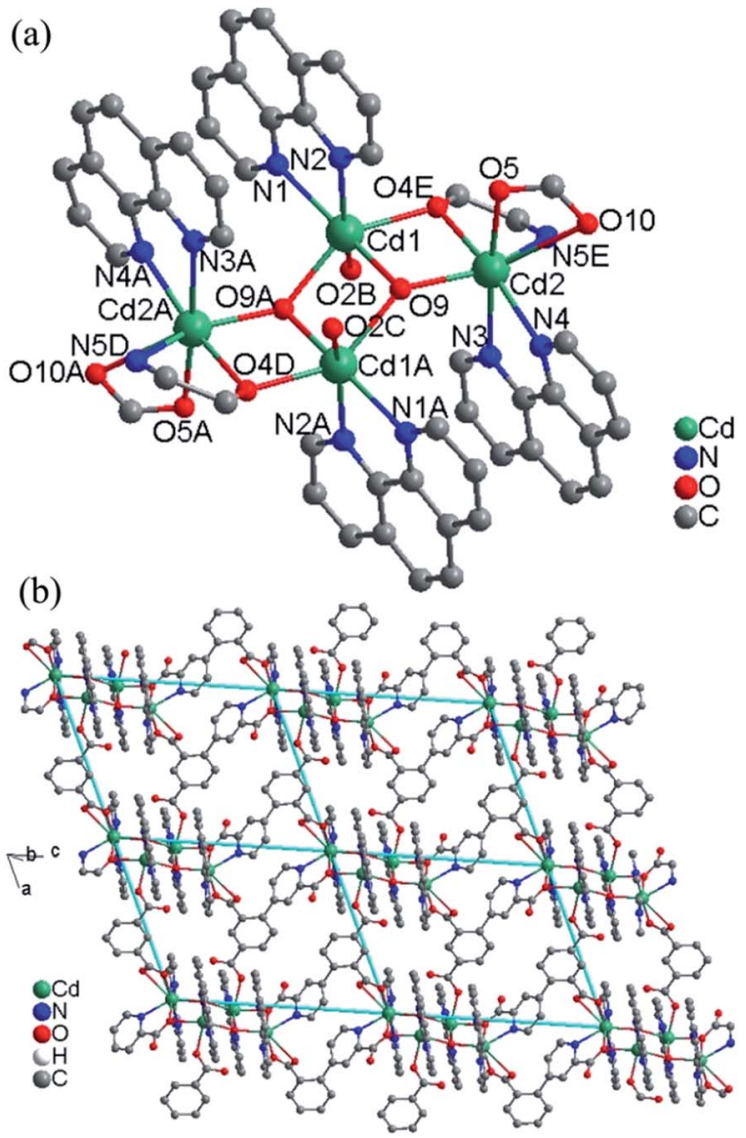

Fig. 2 (a) The tetranuclear cluster in 2 . Symmetry codes: (A) $2-x, 1-$ $y, 1-z$; (B) $1+x, y, z$; (C) $1-x, 1-y, 1-z$; (D) $x, y, 1+z$; (E) $2-x, 1-y$, $-z$. (b) View of the 2D layer of 2 .

on the similar pyridine-tricarboxylate ligands. ${ }^{5 f-h}$ The $\mathrm{Cd} 2$ ion is ligated by three nitrogen atoms (N3, N4 and N5) from one phen and one $\mathrm{L}^{3-}$ ligand, three oxygen atoms ( $\mathrm{O} 4, \mathrm{O} 5$ and $\left.\mathrm{O} 10\right)$ from two $\mathrm{L}^{3-}$ ligands and one hydroxyl oxygen atom (O9) in a distorted mono-capped octahedral $\left[\mathrm{N}_{3} \mathrm{O}_{4}\right]$ coordination geometry with $\mathrm{Cd}-\mathrm{N}$ bond lengths ranging from $2.354(5)$ to $2.441(5) \AA$, Cd-O bond lengths ranging from $2.225(4)$ to $2.418(4) \AA$. The $\mathrm{L}^{3-}$ ligand acts as a hexadentate bridge ligand (mode II, Scheme 2), using one carboxylate oxygen atom (O4) and one nitrogen atom (N5) from picolinic acid to connect with two $\mathrm{Cd}(\mathrm{II})$ ions, one carboxylate group to chelate $\mathrm{Cd}(\mathrm{II})$ ion and a monodentate carboxylate oxygen atom to connect with the fourth $\mathrm{Cd}(\mathrm{II})$ ion. The dihedral angle between the pyridyl and phenol rings in the $\mathrm{L}^{3-}$ is $71.1^{\circ}$.

Each tetranuclear cluster in 2 is linked with four neighbouring tetranuclear clusters by $\mathrm{L}^{3-}$ ligands into $2 \mathrm{D}$ layer along the $a c$ plane (Fig. 2b). The intertetranuclear clusters $\mathrm{Cd} \cdots \mathrm{Cd}$ distances within the layer is in the range of 8.344(1)-21.462(1) ̊. Topologically, Cd(II) ions and ligands can be considered as 4-connected nodes and linkers respectively, thus, the whole structure can be simplified as a 2D 4,4-square-grid layers. The 2D layers are interlinked by the $\mathrm{O}-\mathrm{H} \cdots \mathrm{O}$ hydrogen bonds into 3D network (Fig. S2, ESI†).

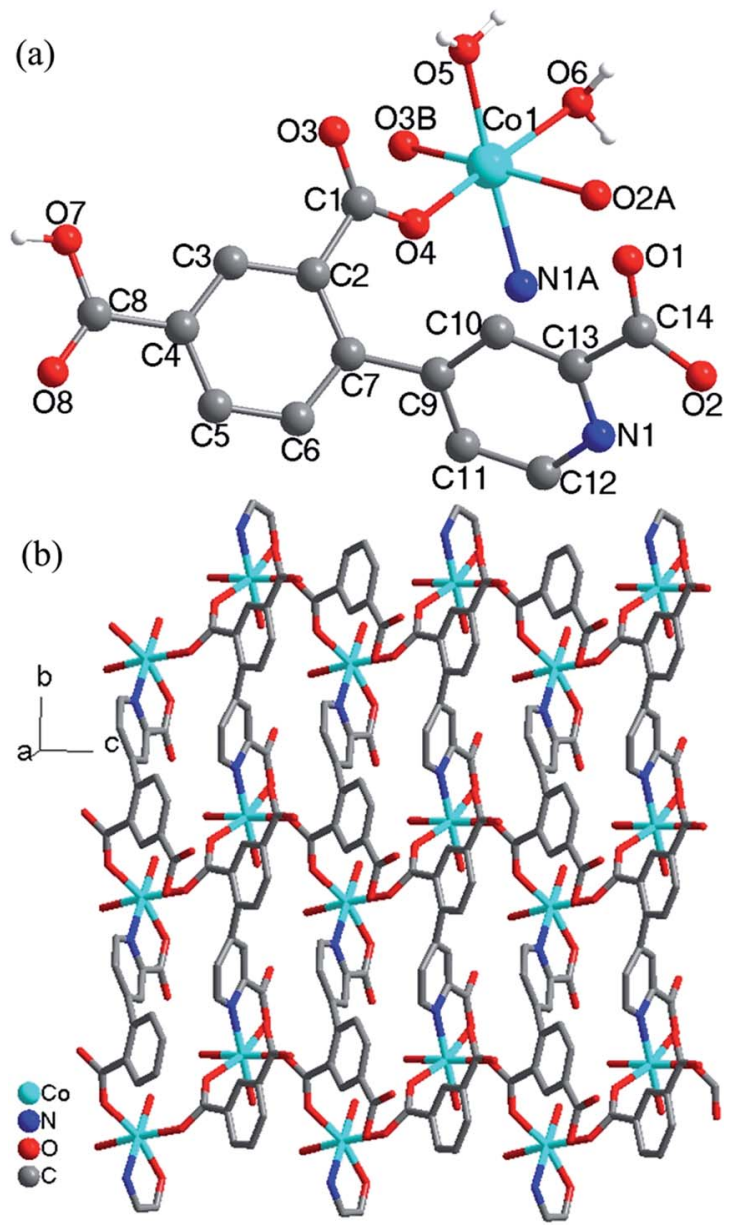

Fig. 3 (a) Local coordination environment of the $\mathrm{Co}^{2+}$ center in 3, symmetry codes: (A) $x, 0.5-y,-0.5+z$; (B) $x, 1.5-y,-0.5+z$. (b) $2 \mathrm{D}$ network formed by the $\mathrm{HL}^{2-}$ ligands connecting the chains.

Crystal structure of 3 . Compound 3 crystallizes in the monoclinic space group $P 2_{(1)} / c$ and exhibits a $2 \mathrm{D}$ framework. The asymmetric unit contains one $\mathrm{Co}(\mathrm{II})$ ion, one $\mathrm{HL}^{2-}$ ligand with one protonated carboxyl group and two deprotonated carboxyl groups and two coordinated water molecules. The coordination environment of the Co(II) ion is shown in Fig. 3a. The unique $\mathrm{Co}(\mathrm{II})$ ion is six-coordinated in a octahedral coordination geometry, ligated by one nitrogen atom and four oxygen atoms from three different $\mathrm{HL}_{1}{ }^{2-}$ ligands and two water molecules with $\mathrm{Co}-\mathrm{N} / \mathrm{O}$ distances in the range of 2.043(2)2.146(1) $\AA$, all the $\mathrm{Co}-\mathrm{O}$ and $\mathrm{Co}-\mathrm{N}$ distances in 3 are comparable to these in other reported $\mathrm{Co}$ (II) compounds based on the similar pyridine-tricarboxylate ligands. ${ }^{5 f . g}$ Neighbouring Co(II) ions are linked by single carboxylate bridges to generate a 1D $[\mathrm{Co}(\mathrm{COO})]_{n}$ chain perpendicular to the $a$ direction (Fig. $\left.3 \mathrm{~b}\right)$. The metal ions are arranged in a zigzag mode along the chain. The carboxylate bridge adopts the syn-anti mode, with the Co1-O4C1-O3 and $\mathrm{Co} 1 \mathrm{~A}-\mathrm{O} 4-\mathrm{C} 1-\mathrm{O} 3$ torsion angles being respectively $2.4(3)^{\circ}$ and $-119.6(2)^{\circ}$. The Co $\cdots$ Co distance separated by the carboxylate bridge is $5.178(5) \AA$. The $\mathrm{HL}^{2-}$ ligand contains a bridging bidentate carboxylate group $\left(\mu_{2}-\eta^{1}: \eta^{1}\right.$-bridging mode), a bidentate picolinic acid which the carboxylate group 
adopts $\mu_{1}-\eta^{1}$ bridging mode and the nitrogen atom (N1) is involved in the coordination, and a noncoordinated carboxylate group (mode III, Scheme 2). The dihedral angle between the pyridyl and phenol rings in the $\mathrm{HL}^{2-}$ is $55.7^{\circ}$.

The $[\mathrm{Co}(\mathrm{COO})]_{n}$ chains are interlinked by the $\mathrm{HL1}^{2-}$ ligands to generate a $2 \mathrm{D}$ layers along the $a$ direction (Fig. 3b). The nearest interchain Co $\cdots$ Co distances within the layer is 7.342(6) $\AA$. The 2D layers are interlinked by the $\mathrm{O}-\mathrm{H} \cdots \mathrm{O}$ hydrogen bonds into 3D network (Fig. S3, ESI $\dagger$ ). According to the literature research, $\mathrm{Co}(\mathrm{II})$ compounds containing $1 \mathrm{D}[\mathrm{Co}(\mathrm{COO})]_{n}$ chains which the $\mathrm{Co}(\mathrm{II})$ ions are bridged by a single carboxylate bridge are rarely reported. ${ }^{9}$

Crystal structure of 4 . Compound 4 crystallizes in the triclinic space group $P \overline{1}$ and exhibits a $3 \mathrm{D}$ framework. The crystallographically independent unit contains three different $\mathrm{Co}(\mathrm{II})$ ions, two $\mathrm{L1}^{3-}$ ligands, eight coordinated water molecules and four lattice water molecules. As shown in Fig. 4a, all three

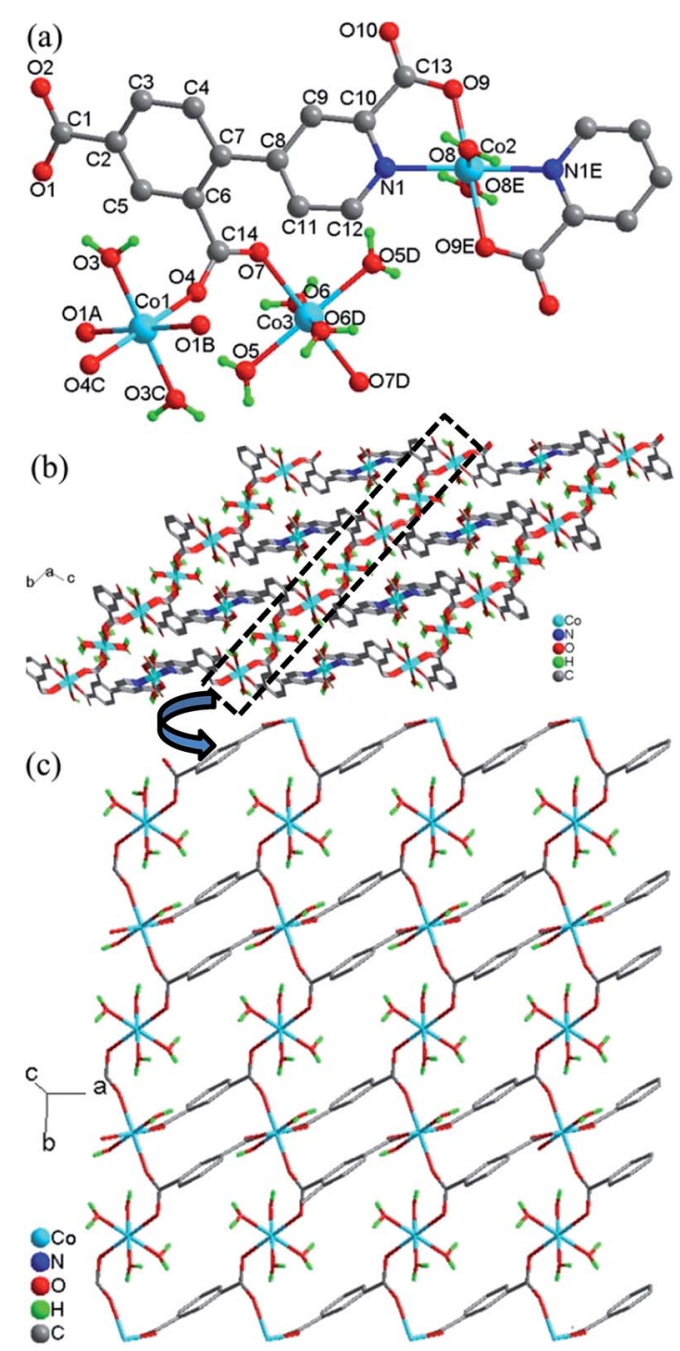

Fig. 4 (a) Local coordination environment of the $\mathrm{Co}^{2+}$ center in 4 symmetry codes: (A) $1-x,-y, 2-z$; (B) $-1+x, y, z$; (C) $-x,-y, 2-z$; (D) $-x, 1-y, 2-z$; (E) $-1-x, 1-y, 1-z$. (b) View of the whole 3D framework of 4 . (c) The unfolded picture of the dotted part of (b) for the structure of 4 .
$\mathrm{Co}(\mathrm{II})$ ions are six-coordinated centrosymmetric trans-octahedral geometry. Both $\mathrm{Co} 1$ and $\mathrm{Co} 3$ ions adopt $\left[\mathrm{O}_{6}\right]$ geometry which the coordination atoms are from the carboxylate oxygen atoms (O1A, O1B and $\mathrm{O} 4, \mathrm{O} 4 \mathrm{C})$ and water molecules (O3 and $\mathrm{O} 3 \mathrm{C}$ ) for $\mathrm{Co1}$; from carboxylate oxygen atoms (O7 and O7D) and water molecules (O5, O5D and O6, O6D) for Co3. Co2 ion adopts $\left[\mathrm{N}_{2} \mathrm{O}_{4}\right]$ geometry which is ligated by the nitrogen atoms (N1 and $\mathrm{N} 1 \mathrm{E}$ ) and the carboxylate oxygen atoms (O9 and O9E) from the $\mathrm{L}^{3-}$ ligands and the water molecules (O8 and $\mathrm{O} 8 \mathrm{E}$ ). The $\mathrm{Co}-\mathrm{O} /$ $\mathrm{N}$ distances are in the range of 2.067(1)-2.133(1) $\AA$, all the Co-O and Co-N distances in $\mathbf{4}$ are comparable to these in other reported $\mathrm{Co}(\mathrm{II})$ compounds based on the similar pyridine-tricarboxylate ligands. ${ }^{5 f, g}$ Co1 and $\mathrm{Co} 3$ ions are single-bridged by carboxylate bridges in the syn-anti mode which is similar with that in 3, with Co1-O4-C14-O7 and Co3-O7-C14-O4 torsion angles being respectively $164.3(1)^{\circ}$ and $-11.5(2)^{\circ}$ which are larger than those in 3 . The Co $\cdots$ Co distance separated by carboxylate bridge is 5.156(3) A which is slightly smaller than that in 3.

The $\mathrm{L}^{3-}$ ligand acts as a $\mu_{4}$ bridge to connect metal ions and contains a bridging bidentate carboxylate group $\left(\mu_{2}-\eta^{1}: \eta^{1}\right.$ bridging mode), a bidentate picolinic acid which the carboxylate group adopts $\mu_{1}-\eta^{1}$ bridging mode and the nitrogen atom (N1) is involved in the coordination, and a mono-coordinated carboxylate group (mode IV, Scheme 2). Along the $b c$ plane, the Co1 and Co3 ions are bridged by ( $\mu$-COO) bridges into $1 \mathrm{D}$ chains along one direction, and $\mathrm{Co} 1(\mathrm{Co} 3)$ and $\mathrm{Co} 2$ ions are also linked by the long $\mathrm{L}^{3-}$ ligands into $1 \mathrm{D}$ chains $(\mathrm{Co} 1 \cdots \mathrm{Co} 2=$ 9.916(4) $\AA$, Co3 $\cdots \mathrm{Co} 2=6.422(4) \AA)$ along the other direction, and the angle along the chain of two direction is $26.4(1)^{\circ}$ (Fig. 4b). Nevertheless, along the $a b$ plane (Fig. 4c), the chains bridged by the single ( $\mu$-COO) bridges between Co1 and Co3 ions are along one direction while the chains linked by the same long $\mathrm{L1}^{3-}$ ligands between $\mathrm{Co} 1$ and $\mathrm{Co} 1$ (Co3) ions are along two different directions with Co1 $\cdots \mathrm{Co} 1=7.196(6) \AA$ and $\mathrm{Co} 1 \cdots \mathrm{Co} 3$ $=9.001(5) \AA$. Thus, the structure of 3D framework in 4 can be understood in this way: Co1 and Co3 ions are bridged/ interlinked by $\mathrm{L}^{3-}$ along the $a b$ plane into $2 \mathrm{D}$ layers while the Co2 ions interlinked with $\mathrm{Co} 1$ and $\mathrm{Co} 3$ ions by long $\mathrm{L1}^{3-}$ ligands are in the plane just perpendicular to the $a b$ plane. This complicated $3 \mathrm{D}$ framework can be formed just owing to the rotation of the $\mathrm{C}-\mathrm{C}$ bond between the phenyl ring and pyridyl ring, and the dihedral angle is $36.7^{\circ}$.

Crystal structure of $\mathbf{5}$. The structure of $\mathbf{5}$ consists of 2D layers based on trinuclear $\left[\mathrm{Mn}_{3}(\mathrm{COO})_{6}\left(\mathrm{H}_{2} \mathrm{O}\right)_{2}\right]$ units. As shown in Fig. 5a, there are two crystallographically independent $\mathrm{Mn}$ (II) ions in 5 (Mn1 and Mn2). Mn1 adopts the centrosymmetric trans-octahedral $\left[\mathrm{O}_{6}\right]$ geometry completed by two axial carboxylate oxygen atoms ( $\mathrm{O} 2$ and $\mathrm{O} 2 \mathrm{~A})$ and four equatorial carboxylate oxygen atoms (O5B, O5C, O7D and O7E). Mn2 assumes a distorted $\left[\mathrm{NO}_{5}\right]$ geometry defined by four carboxylate oxygen atoms $(\mathrm{O} 2, \mathrm{O} 3, \mathrm{O} 4 \mathrm{~B}$ and $\mathrm{O} 6 \mathrm{E})$, one water molecule $(\mathrm{O} 1)$ and a nitrogen atom (N1) from 4,4'-bpy. The Mn-N/O bond distances for both Mn1 and Mn2 fall in the range of 2.128(3)2.654(4) A while Mn2-O3 can be taken as weak coordination with the longer bond distances 2.654(4) A. Each Mn1 is connected with two Mn2 ions to give a trinuclear 

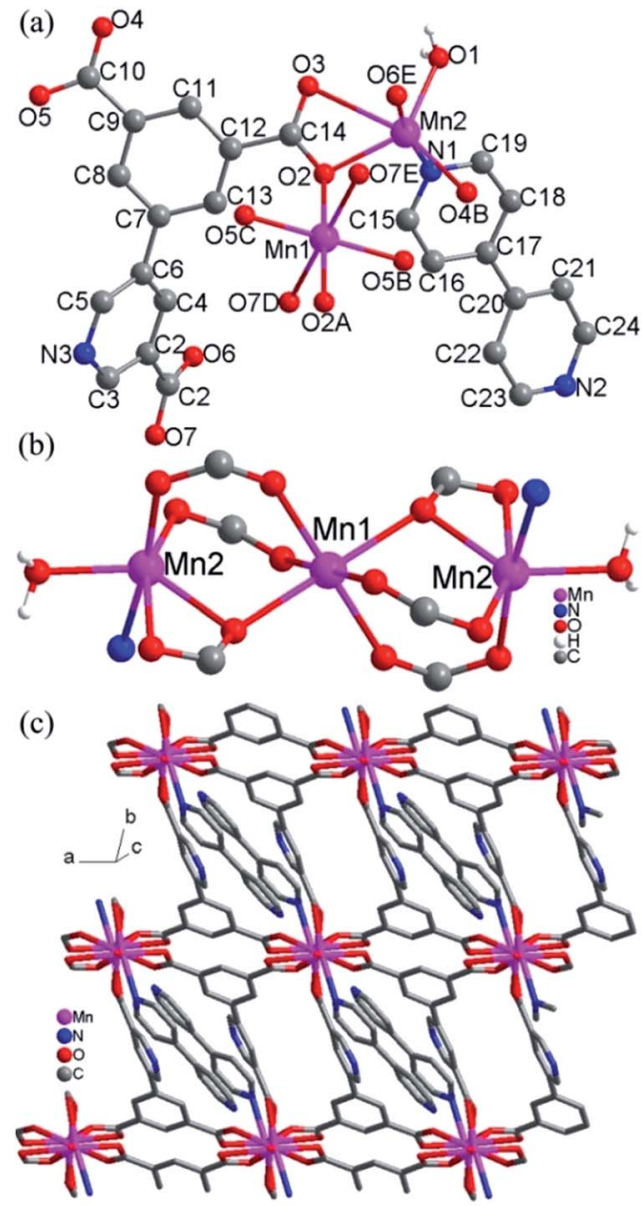

Fig. 5 (a) Local coordination environments of $\mathrm{Mn}^{2+}$ centers and the ligands in 5, symmetry codes: (A) $-x, 1-y,-z$; (B) $1+x, y, z$; (C) $-1-x$, $1-y_{1}-z$; (D) $-x, 2-y_{1}-z$; (E) $x,-1+y, z$. (b) The trinuclear units in 5 . (c) 2D layers formed by trinuclear units and ligands $L^{2}$ in 5 .

$\left[\mathrm{Mn}_{3}(\mathrm{COO})_{6}\left(\mathrm{H}_{2} \mathrm{O}\right)_{2}\right]$ unit (Fig. $\left.5 \mathrm{~b}\right)$, in which the triple bridges consist of $(\mu-\mathrm{COO})_{2}\left(\mu_{2}-\mathrm{O}_{\text {carboxylate }}\right)$. The $\mathrm{Mn} \cdots \mathrm{Mn}$ distances spanned by the triple bridges are $3.52 \AA$, with $\mathrm{Mn}-\mathrm{O}-\mathrm{Mn}=$ 105.99(1) ${ }^{\circ}$. These angles and distances are similar to those observed for previous $\mathrm{Mn}$ (II) compounds with similar bridges. ${ }^{10}$ The trinuclear $\mathrm{Mn}$ (II) compounds with similar bridges have been observed in some discrete molecular species with monocarboxylate, ${ }^{10 a-d}$ a few extended frameworks with dicarboxylate ligands ${ }^{10 e, 11}$ and a chain compound with a zwitterionic dicarboxylate ligand..$^{10 f}$

The $\mathrm{L}^{3-}$ ligands act as $\mu_{6}$ bridges in which two carboxylate groups adopt $\mu_{2}-\eta^{1}: \eta^{1}$-bridging modes, the third carboxylate group adopts $\mu_{2}-\eta^{1}: \eta^{2}$-bridging mode and the nitrogen atoms of $\mathrm{L}^{3-}$ are not involved in coordination (mode V, Scheme 2). The dihedral angle between the $m$-phthalic acid plane and the picolinic acid plane of $\mathrm{L}^{3-}$ is $120.40(4)^{\circ}$. Neighbouring trinuclear $\mathrm{Mn}_{3}$ units are interlinked by $\mathrm{L}^{3-}$ ligands into 2D 4,4-grid layers along the $c$ direction (Fig. $5 \mathrm{c}$ ). The $4,4^{\prime}$-bpy molecules are mono-coordinated with the $\mathrm{Mn}$ (II) ions and locate in the grid formed by $\mathrm{Mn}_{3}$ units and the $\mathrm{L}^{3-}$ ligands. The $2 \mathrm{D}$ layers are interlinked by the $\mathrm{O}-\mathrm{H} \cdots \mathrm{O}$ and $\mathrm{O}-\mathrm{H} \cdots \mathrm{N}$ hydrogen bonds into 3D network (Fig. S4, ESI†)).

\section{Thermogravimetric analyses and PXRD patterns}

Thermogravimetric analyses (TGA) were studied on compounds 1-5 (Fig. S5, ESI $\dagger$ ). Compound 1 shows a gradual weight loss of $5 \%$ from $25-412{ }^{\circ} \mathrm{C}$, suggesting the gradual decomposition of the framework, and the further sharp weight loss corresponding to the full collapse of the framework of $\mathbf{1}$. Compound 2 exhibits an initial weight loss of $2 \%$ in the temperature range of $25-$ $165^{\circ} \mathrm{C}$, corresponding to the loss of all lattice water molecules (calcd, 3.9\%), and then there is continuous weight loss above $165^{\circ} \mathrm{C}$, due to the collapse of the framework of 2 . Compound 3 shows no any weight loss in the range of $25-152^{\circ} \mathrm{C}$ while shows weight loss of $9.3 \%$ in the range of $153-400^{\circ} \mathrm{C}$, corresponding to the loss of all coordinated water molecules (calcd, 10\%). The further weight drop above $400{ }^{\circ} \mathrm{C}$ suggests the decomposition of the framework. Compound 4 shows a gradual weight loss of $22.2 \%$ from $25-400{ }^{\circ} \mathrm{C}$, corresponding to the loss of all lattice and coordinated water molecules (calcd, 22.5\%), and the further weight loss corresponding to the decomposition of the framework. Compound 5 exhibits no any weight loss in the range of $25-155{ }^{\circ} \mathrm{C}$ while shows weight loss of $3.7 \%$ in the relatively narrow range of $155-198{ }^{\circ} \mathrm{C}$, corresponding to the coordinated water molecules (calcd, $4 \%$ ), and then, there is an initially slow then fast weight loss above $198{ }^{\circ} \mathrm{C}$ due to the decomposition of the framework of 5 . The observed weight loss values are somewhat less than that expected from the crystallographic data, suggesting the partial loss of water before the measurements.

The PXRD patterns for 1-5 are shown in Fig. S6-S10 in the ESI. $\uparrow$ The diffraction peaks of both calculated and observed patterns match well indicative of the purity of the samples. The difference in reflection intensities between the simulated and observed patterns is owing to the different orientation of the crystals in the powder samples.

\section{Photoluminescence}

Luminescence properties of $\mathrm{Zn}$ (II) and $\mathrm{Cd}(\mathrm{II})$ coordination compounds have attracted great attention, due to their potential applications in chemical sensors, photochemistry and electroluminescence displays. ${ }^{12}$ Here we investigated the solid luminescence properties of compounds $\mathbf{1}$ and 2 at room temperature (Fig. 6). The free $\mathrm{H}_{3} \mathrm{~L} 1$ ligand exhibits a single broad luminescence emission between $350 \mathrm{~nm}$ and $550 \mathrm{~nm}$ with a maximum peak at $398 \mathrm{~nm}\left(\lambda_{\mathrm{ex}}=330 \mathrm{~nm}\right)$. Free phen shows a very intense emission band at $437 \mathrm{~nm}\left(\lambda_{\mathrm{ex}}=360 \mathrm{~nm}\right)$. The emissions of the organic ligands may be ascribed to the intraligand $\pi^{*} \rightarrow \pi$ or $\pi^{*} \rightarrow \mathrm{n}$ transitions. ${ }^{13}$ Upon complexation of the ligands with $\mathrm{Zn}$ (II) and $\mathrm{Cd}(\mathrm{II})$ ions, the emission peaks occur at $534 \mathrm{~nm}\left(\lambda_{\mathrm{ex}}=330 \mathrm{~nm}\right)$ for $1,429 \mathrm{~nm}\left(\lambda_{\mathrm{ex}}=370\right.$ $\mathrm{nm}$ ) for $\mathbf{2}$. For compound $\mathbf{1}$, the emission peak is highly redshift by $136 \mathrm{~nm}$ with respect to the free $\mathrm{H}_{3} \mathrm{~L} 1$ ligand which may be caused by the variations of the highest occupied molecular orbital (HOMO) and lowest unoccupied molecular orbital (LUMO) energy levels after the organic ligands coordinate to the metal ions. It is difficult to oxidize or to reduce to the $\mathrm{d}^{10}$ configuration of $\mathrm{Zn}$ (II) ions, the emission of this compound is neither MLCT nor LMCT in nature. ${ }^{13 b, 14}$ Therefore, the 


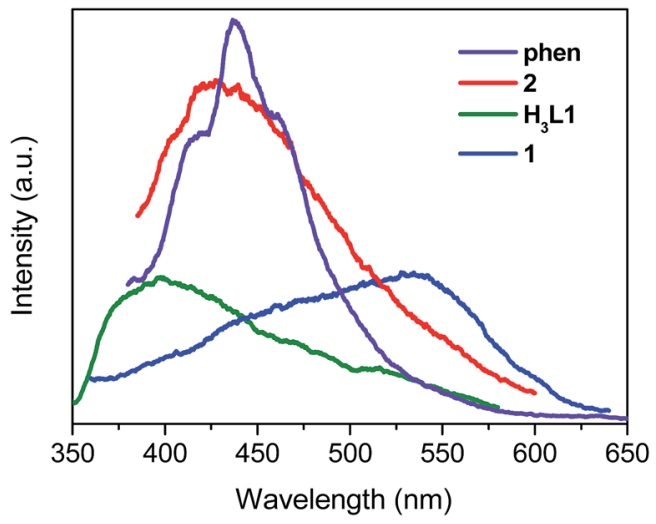

Fig. 6 The solid-state emission spectra of free $\mathrm{H}_{3} \mathrm{~L} 1$, phen, 1 and 2 at room temperature.

emission bands of compound $\mathbf{1}$ can be assigned to intraligand luminescence emissions. For compound 2, it exhibits emission peak at $429 \mathrm{~nm}\left(\lambda_{\mathrm{ex}}=370 \mathrm{~nm}\right)$ which are red-shifted with respect to free $\mathrm{H}_{3} \mathrm{~L} 1$ ligands and phen. Thus, the emission of 2 could be attributed to a mixture of characteristics of intraligand and ligand-to-ligand charge transition (LLCT) as reported by others for other $\mathrm{d}^{10}$ metal complexes with $\mathrm{N}$-donor ligands. ${ }^{5 h, 15}$ The decay dynamics of the emission bands at $534 \mathrm{~nm}$ for $\mathbf{1}$ and $429 \mathrm{~nm}$ for 2 can be well fitted by the double-exponential curve, and their lifetimes are 1.73 and $1.06 \mathrm{~ms}$, respectively (Fig. S11 and S12, ESI $\dagger$ ).

\section{Magnetic properties}

Compounds 3 and 4. The thermal magnetic properties of 3 and 4 were measured under 1000 Oe in the temperature range 2-300 K (Fig. 7 and 8). The two compounds show similar magnetic temperature-dependent behaviours. The $\chi T$ values per cobalt for 3 and per $\mathrm{Co}_{3}$ unit for 4 at $300 \mathrm{~K}$ (3.07 and 8.99 emu $\mathrm{K} \mathrm{mol}^{-1}$ ) are much higher than the spin-only values 1.875 emu K mol${ }^{-1}$ for one $S=3 / 2$ ion in 3 , and $5.62 \mathrm{emu} \mathrm{K} \mathrm{mol}^{-1}$ for three $S=3 / 2$ ions in 4 , indicative of the presence of an

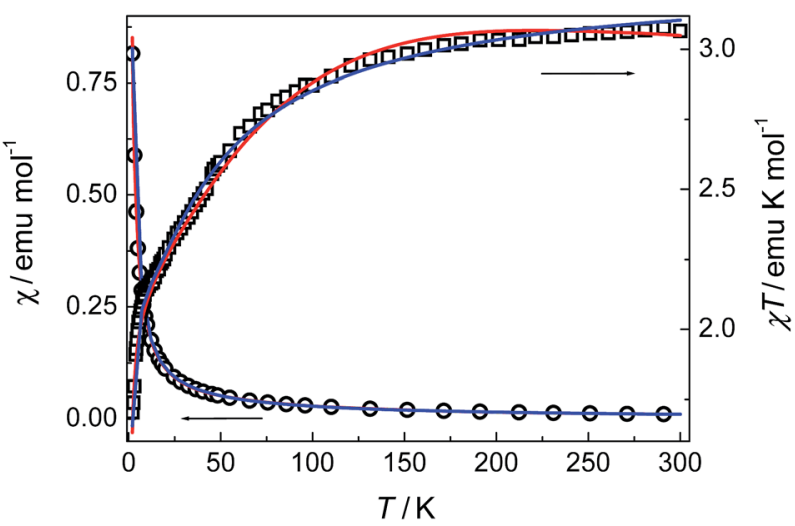

Fig. 7 Plots of $\chi$ and $\chi T$ against $T$ for 3 . The solid lines represent the best fits of the data by different equations (see the text): red, eqn (1)(3); blue, eqn (4).

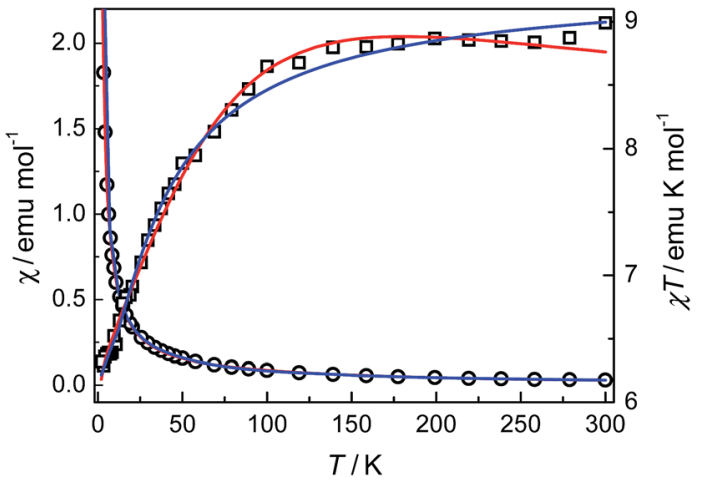

Fig. 8 Plots of $\chi$ and $\chi T$ against $T$ for 4 . The solid lines represent the best fits of the data by different equations (see the text): red, eqn (1)(3); blue, eqn (4).

unquenched orbital moment typical of pseudo-octahedral Co(II). As shown in Fig. 7 and 8, the $\chi T$ values decrease monotonically upon cooling in the whole temperature range studied, reaching a value of $1.7 \mathrm{emu} \mathrm{K} \mathrm{mol}^{-1}$ for 3 and $6.16 \mathrm{emu} \mathrm{K} \mathrm{mol}^{-1}$ for 4 at $2 \mathrm{~K}$, while $\chi$ increases continuously for 3 and 4 . The data above $20 \mathrm{~K}$ (3) and $64 \mathrm{~K}$ (4) follow the Curie-Weiss law with $C=$ $3.18 \mathrm{emu} \mathrm{K} \mathrm{mol}{ }^{-1}, \theta=-10.4 \mathrm{~K}$ for 3 and $C=9.12 \mathrm{emu} \mathrm{K} \mathrm{mol}^{-1}$, $\theta=-6.7 \mathrm{~K}$ for 4 . The relatively small negative $\theta$ values indicate weak $\mathrm{AF}$ coupling between adjacent $\mathrm{Co}$ (II) ions in $\mathbf{3}$ and $\mathbf{4}$, which was found in a $\mathrm{Co}$ (II) compound with similar bridging mode. ${ }^{9} \mathrm{As}$ far as we know, it was very rarely reported for the examples of Co(II) complexes bridged by single syn-anti carboxylate bridge and their magnetic properties further. ${ }^{9}$

Owing to the inherent complication related to the single-ion anisotropy, it is always difficult to exactly evaluate the magnetic parameters for $\mathrm{Co}$ (II) systems, and some models at different levels of approximation have been applied. ${ }^{16}$ Here we have tried two approaches. We firstly employed the effective-spin approach proposed by Lloret et al. ${ }^{17,18}$

In this approach, the Co(II) ion is treated as $S_{\text {eff }}=1 / 2 \mathrm{spin}$, which is related to the real spin $(S=3 / 2)$ by eqn (1), and the effective spin Hamiltonian for a uniform chain is expressed as eqn (2).

$$
\begin{gathered}
S=(5 / 3) S_{\mathrm{eff}} \\
H=-(25 / 9) J \sum S_{\mathrm{eff}, i} S_{\mathrm{eff}, j}-G(T, J) \beta H \sum S_{\mathrm{eff}, i}
\end{gathered}
$$

where the fictitious Landé factor $G(T, J)$ is a temperature dependent function including four parameters: $\lambda$ (spin-orbital coupling parameter), $\alpha$ (orbital reduction factor), $\Delta$ (ligand-field distortion factor, assuming an axial distortion), and $J$ (magnetic exchange parameter). Combining this approximation and the polynomial expression for the susceptibility of AF half-spin chains $^{18,19}$ [eqn (3)]:

$$
\chi_{\text {chain }}=N \beta^{2}[G(T, J)]^{2} /(k T)[A / B]
$$

where $A=0.25+0.14995 x+0.30094 x^{2}$, and $B=1+1.9862 x+$ $0.68854 x^{2}+6.0626 x^{3}$ with $x=25|J| /(18 k T)$. It is noted that the 
system of 4 can be treated as 1D Co(II) chains (formed by single carboxylate-bridged Co1 and Co3 ions) plus mononuclear Co(II) species (Co2) according to the structural data, because $\mathrm{Co} 2$ ions are linked with $\mathrm{Co} 1$ and $\mathrm{Co} 3$ through long $\mathrm{H}_{3} \mathrm{~L} 1$ ligands and the magnetic interactions through long $\mathrm{H}_{3} \mathrm{~L}^{1}$ ligands can be ignored. The magnetic contribution of the chain $\left(\chi_{\text {chain }}\right)$, in which magnetic coupling $(J)$ is mediated through the single carboxylate bridge. Then, according to the stoichiometry of the compound, the total susceptibility is $\chi=\chi_{\text {chain }}+\chi_{\text {mono }}$, where $\chi_{\text {mono }}=N g^{2} \beta^{2} S(S+1) / 3 k T$ is the contribution from the mononuclear component. The best fits gave $J=-0.26 \mathrm{~cm}^{-1}, \lambda=-123$ $\mathrm{cm}^{-1}, \alpha=1.44$, and $\Delta=-967 \mathrm{~cm}^{-1}$ for 3 , and $J=-0.01 \mathrm{~cm}^{-1}, \lambda$ $=-142 \mathrm{~cm}^{-1}, \alpha=0.97$, and $\Delta=-624 \mathrm{~cm}^{-1}$ for 4 . The small negative $J$ values support weak AF interactions through the single carboxylate bridges in $\mathbf{3}$ and $\mathbf{4}$, and the values of the single-ion parameters $\lambda, \alpha$ and $\Delta$ for $\mathbf{3}$ and $\mathbf{4}$ fall within the most common ranges expected for octahedral Co(II) compounds and the $J$ values suggest the occurrence of weak AF interactions through the single carboxylate bridge in 3 and 4 . The carboxylate bridge usually induces AF coupling in the syn-syn and anti-anti mode, but the syn-anti mode may lead to weak antiferro- or ferromagnetic coupling. ${ }^{18,20}$ After the literature research, we have found that most of the carboxylate bridged $\mathrm{Co}$ (II) coordination polymers are double carboxylate bridged while the related reports about $\mathrm{Co}$ (II) coordination compounds bridged by only single syn-anti carboxylate bridge between Co(II) ions and the related magnetic properties were very rare. ${ }^{9}$ Compounds 3 and $\mathbf{4}$ are two new examples which Co(II) ions are bridged only by a single syn-anti carboxylate bridge and their magnetic analyses were well done, and our magnetic fit results for $\mathbf{3}$ and $\mathbf{4}$ are in accordance with that in literature. ${ }^{9}$

Secondly, we adopt the simple phenomenological equation given as eqn (4) proposed by Rueff et al. for low-dimensional Co(II) systems: ${ }^{18,21,22}$

$$
\chi T=A \exp \left(-E_{1} / k T\right)+B \exp \left(-E_{2} / k T\right)
$$

in which $A+B$ is close to the Curie constant $C$, and $E_{1}$ and $E_{2}$ are the "activation energies" associated with single-ion effects and magnetic exchange interactions, respectively. ${ }^{21}$ This approach allows one to have rough estimation of the strength of the magnetic exchange interactions.

Very good results have been demonstrated in $1 \mathrm{D}$ and $2 \mathrm{D}$ Co(II) compounds which $E_{1} / k$, spin-orbit coupling and site distortion, is on the order of $+100 \mathrm{~K}$ in almost all of these compounds. As shown in Fig. 7 and 8, the fits using the above expression is quite satisfactory in the whole temperature range. The values obtained are $A+B=3.25 \mathrm{emu} \mathrm{K} \mathrm{mol}^{-1}, E_{1} / k=+34.9$ $\mathrm{K}$, and $E_{2} / k=+0.43 \mathrm{~K}$ for 3 ; and $A+B=9.31 \mathrm{emu} \mathrm{K} \mathrm{mol}^{-1}, E_{1} / k=$ $+24.4 \mathrm{~K}$, and $E_{2} / k=+0.05 \mathrm{~K}$ for 4 . The $A+B$ values are comparable with the Curie constants obtained reported by the CurieWeiss fittings (see above). The $E_{1} / k$ values accounting for the effect of spin-ion coupling and site distortion are also consistent with literature values of the order of $+100 \mathrm{~K}$. The signs of $-E_{2} / k$ clearly indicate weak AF exchange interactions. The values correspond to $J / k=-0.43 \mathrm{~K}$ (i.e., $J=-0.3 \mathrm{~cm}^{-1}$ ) for 3 and $J / k=-0.05 \mathrm{~K}\left(\right.$ i.e.,$\left.J=-0.03 \mathrm{~cm}^{-1}\right)$ for 4 . It is interesting to note that the $J$ values are comparable with the $J=-0.26 \mathrm{~cm}^{-1}$ for 3 and $J=-0.01 \mathrm{~cm}^{-1}$ for 4 values obtained from the above firstly used effective-spin approach.

The weak AF interactions in $\mathbf{3}$ and $\mathbf{4}$ are confirmed by the isothermal magnetization measured at $2 \mathrm{~K}$ (Fig. 9). As the field is increased from 0 to $50 \mathrm{kOe}$, the magnetization increases slowly in the low field region and is quasi linear in the field range of $0-10 \mathrm{kOe}$ for both 3 and 4 . The magnetization values of 3 and 4 at 50 kOe are $2.63 N \beta$ and $7.75 N \beta$ respectively, which are in the usual ranges expected for one or three high-spin Co(II) ions with orbital degeneracy.

Compound 5. The magnetic susceptibility of compound $\mathbf{5}$ was measured on a polycrystalline sample under $1 \mathrm{kOe}$ in the range of $2-300 \mathrm{~K}$ (Fig. 10). The measured $\chi T$ value at $300 \mathrm{~K}$ is about $13.17 \mathrm{emu} \mathrm{K} \mathrm{mol}^{-1}$, almost the same as the spin-only value (13.13 emu $\mathrm{K} \mathrm{mol}^{-1}$ ) for three uncoupled $\mathrm{Mn}$ (II) ions with $g=2.00$. As the sample is cooled from room temperature, the value of $\chi$ increases continuously, while the $\chi T$ value decreases continuously to a minimum value of about $4.01 \mathrm{emu}$ $\mathrm{K} \mathrm{mol}^{-1}$ at $2 \mathrm{~K}$. The data above $35.5 \mathrm{~K}$ follow the Curie-Weiss law with $C=14.36 \mathrm{emu} \mathrm{K} \mathrm{mol}{ }^{-1}$ and $\theta=-30.2 \mathrm{~K}$, indicating $\mathrm{AF}$ coupling interactions between the $\mathrm{Mn}$ (II) centers.

The system can magnetically be regarded as an isolated linear trinuclear system. The Heisenberg Hamiltonian for the trinuclear system can be written as $H=-J\left(S^{\mathrm{c}} S^{\mathrm{t} 1}+S^{\mathrm{c}} S^{\mathrm{t} 2}\right)$, where $J$ is the exchange constant between the terminal ( $\operatorname{spin} S^{\mathrm{t} 1}$ or $\left.S^{\mathrm{t} 2}\right)$ and central $\left(S^{\mathrm{c}}\right)$ metal ions. By application of van Vleck's equation, an analytical expression of magnetic susceptibility for the trinuclear system can be deduced. ${ }^{\mathbf{1 0 d , 1 9}}$ The best fit parameters are $J=-3.75 \mathrm{~cm}^{-1}$ and $g=2.05$, suggesting a weak AF interaction through the triple bridge composed of $(\mu-\mathrm{COO})_{2}\left(\mu_{2}-\right.$ $\left.\mathrm{O}_{\text {carboxylate }}\right)$. We note that although some compounds with similar bridges in the previous related reports were characterized structurally and magnetically, no clear correlations was found between the structural parameters and the $J$ values due to the complexity arising from the coexistence of mixed oxygen and carboxylate bridges. Compound 5 shows moderate $\mathrm{AF}$ interaction than the previous compounds which may be accounted for the medium Mn- $\mathrm{O}_{\text {bridge }}$ distance $(2.19 \AA, 2.22 \AA$ ) and the $\mathrm{Mn} \cdots \mathrm{Mn}$ distance compared with the previous reported compounds. ${ }^{10,23}$

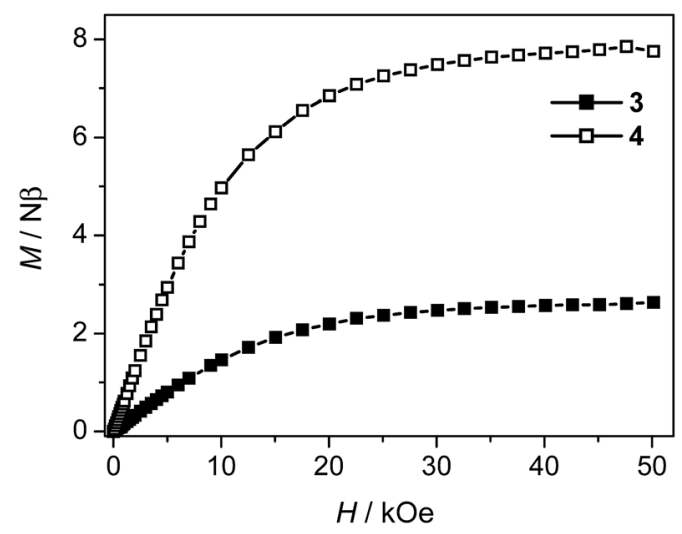

Fig. 9 Magnetization isotherms for 3 and 4 at $2 \mathrm{~K}$. 


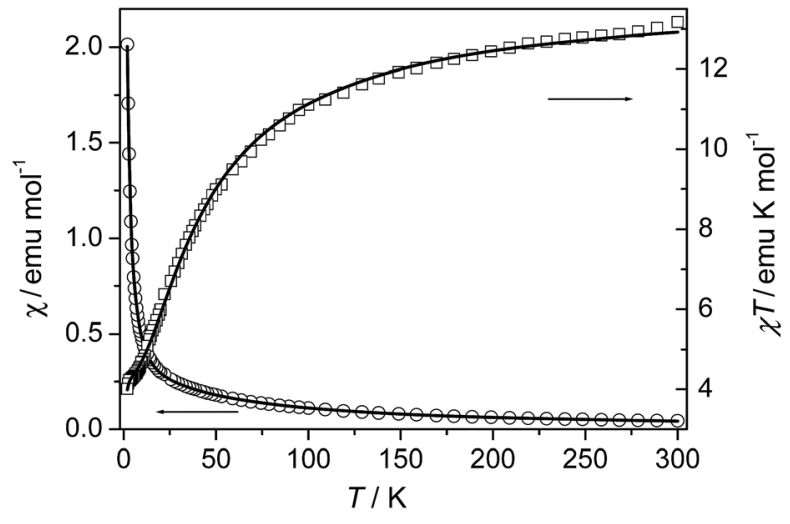

Fig. 10 Temperature dependence of $\chi$ and $\chi^{T}$ for 5 . The solid lines represent the best fits to the trinuclear model (see the text).

\section{Conclusions}

In this work, we have opened up the application of two $\pi$ conjugated pyridyl-tricarboxylate ligands, 4-(2,4-dicarboxylphenyl) picolinic acid ( $\left.\mathrm{H}_{3} \mathrm{~L} 1\right), 5$ - $\left(3^{\prime}, 5^{\prime}\right.$-dicarboxylphenyl) nicotinic acid $\left(\mathrm{H}_{3} \mathrm{~L} 2\right)$ as the novel multifunctional tricarboxylate ligands containing a pyridine functionality for the construction of the different $2 \mathrm{D}$ or $3 \mathrm{D}$ coordination polymers. Thus, five coordination polymers have been successfully generated by hydrothermal self-assembly reactions, using different $\mathrm{Zn(II),}$ $\mathrm{Cd}(\mathrm{II}), \mathrm{Co}(\mathrm{II})$ and $\mathrm{Mn}$ (II) salts and $\mathrm{H}_{3} \mathrm{~L} 1$ or $\mathrm{H}_{3} \mathrm{~L} 2$ as the unexplored ligands in the absence or presence auxiliary ligands. Compounds 1, 2, 3 and 5 all contain 2D layers based on $[\mathrm{Zn}(\mu-$ $\left.\mathrm{O}_{\text {carboxylate }}(\mathrm{COO})\right]_{n}$ chains, tetranuclear $\left[\mathrm{Cd}_{4}\left(\mu_{3}-\mathrm{OH}\right)_{2}(-\right.$

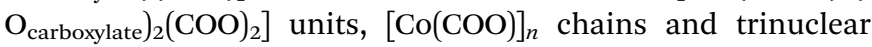
$\left[\mathrm{Mn}_{3}(\mathrm{COO})_{6}\left(\mathrm{H}_{2} \mathrm{O}\right)_{2}\right]$ units respectively. Compound 4 consists of $3 \mathrm{D}$ framework which the 2D layers are further interlinked by Co(II) ions. Both compounds 1 and 2 show intense luminescence in the solid state at room temperature. Magnetic studies for 3-5 demonstrated that the single $\mu$-COO bridge transmits weak AF interactions between $\mathrm{Co}$ (II) ions in $\mathbf{3}$ and $\mathbf{4}$ while the mixed $\left(\mu-\mathrm{O}_{\text {carboxylate }}\right)(\mathrm{COO})_{2}$ bridges transmit moderate AF interactions between $\mathrm{Mn}(\mathrm{II})$ ions in $\mathbf{5}$.

\section{Acknowledgements}

We are thankful for the financial support from NSFC (21301087, 21361016), the Inner Mongolia autonomous region natural science fund project (2013MS0206), and Programs of Higherlevel talents of Inner Mongolia University (SPH-IMU-30105125135).

\section{Notes and references}

1 (a) D. B. Dang, P. Y. Wu, C. He, Z. Xie and C. Y. Duan, J. Am. Chem. Soc., 2010, 132, 14321; (b) M. Eddaoudi, D. F. Sava, J. F. Eubank, K. Adil and V. Guillerm, Chem. Soc. Rev., 2015, 44, 228; (c) L. J. Murray, M. Dincă and J. R. long, Chem. Soc. Rev., 2009, 38, 1294; (d) M. D. Allendor, C. A. Bauer, R. K. Bhakta and R. J. T. Houk, Chem. Soc.
Rev., 2009, 38, 1330; (e) M. Kurmoo, Chem. Soc. Rev., 2009, 38, 1353; (f) Y. X. Guo, X. Feng, T. Y. Han, S. Wang, Z. G. Lin, Y. P. Dong and B. Wang, J. Am. Chem. Soc., 2014, 136, 15485; (g) D. Zacher, O. Shekhah, C. Wöll and R. A. Fischer, Chem. Soc. Rev., 2009, 38, 1418; (h) J. R. Li, R. J. Kuppler and H. C. Zhou, Chem. Soc. Rev., 2009, 38, 1477; (i) Y. B. He, O. Keefe and B. L. Chen, Chem. Soc. Rev., 2014, 43, 5618.

2 (a) B. Zheng, H. Dong, J. Bai, Y. Li, S. Li and M. Scheer, J. Am. Chem. Soc., 2008, 130, 7778; (b) A. M. Stepenson and D. Ward, Chem. Commun., 2012, 48, 3605; (c) L. S. Long, CrystEngComm, 2010, 12, 1354; (d) K. H. Li, W. C. Song, Y. W. Li, Y. Q. Chen and X. H. Bu, Cryst. Growth Des., 2012, 12, 1064; (e) X. M. Chen and M. L. Tong, Acc. Chem. Res., 2007, 40, 162; (f) L. N. Zhang, C. Zhang, B. Zhang, C. X. Du and H. W. Hou, CrystEngComm, 2015, 17, 2837.

3 (a) M. Higuchi, K. Nakamura, S. Horike, Y. Hijikata, N. Yanai, T. Fukushima, J. Kim, K. Kato, M. Takata, D. Watanabe, S. Oshima and S. Kitagawa, Angew. Chem., Int. Ed., 2012, 51, 8369; (b) J. C. Yu, Y. J. Cui, C. D. Wu, Y. Yang, B. L. Chen and G. D. Qian, J. Am. Chem. Soc., 2015, 137, 4026; (c) X. T. Rao, J. F. Cai, J. C. Yu, Y. B. He, C. D. Wu, W. Zhou, T. Yildirim, B. L. Chen and G. D. Qian, Chem. Commun., 2013, 49, 6719; (d) B. Liu, W. P. Wu, L. Hou and Y. Y. Wang, Chem. Commun., 2014, 50, 8731.

4 (a) Y. Q. Wang, Q. H. Tan, H. T. Liu, W. Sun and Z. L. Liu, RSC $A d v .$, 2015, 5, 86614; (b) Q. H. Tan, Y. Q. Wang, X. Y. Guo, H. T. Liu and Z. L. Liu, RSC Adv., 2016, 6, 61725; (c) Y. Q. Wang, Q. Yue and E. Q. Gao, Chem.-Eur. J., 2017, 23, 896; (d) Y. Q. Wang, A. L. Cheng, P. P. Liu and E. Q. Gao, Chem. Commun., 2013, 49, 6995; (e) Y. Q. Wang, Q. H. Tan, X. Y. Guo, H. T. Liu, Z. L. Liu and E. Q. Gao, RSC Adv., 2016, 6, 72326.

5 (a) N. N. Yang, W. Sun, F. G. Xi, Q. Sui, L. J. Chen and E. Q. Gao, Chem. Commun., 2017, 53, 1747; (b) T. Gong, X. Yang, Q. Sui, Y. Qi, F. G. Xi and E. Q. Gao, Inorg. Chem., 2016, 55, 96; (c) Q. Yang, J. P. Zhao, B. W. Hu, X. F. Zeng and X. H. Bu, Inorg. Chem., 2010, 49, 3746; (d) L. M. Fan, W. L. Fan, B. Lin, X. Z. Liu, X. Zhao and X. T. Zhang, CrystEngComm, 2015, 17, 4669; (e) J. Q. Liu, X. F. Li, C. Y. Gu, J. C. S. Silva, A. L. Barros, S. Alves Jr, B. H. Li, F. Ren, S. R. Batten and T. A. Soares, Dalton Trans., 2015, 44, 19370; (f) Y. L. Shao, Y. H. Cui, J. Z. Gu, A. M. Kirillov, J. $\mathrm{Wu}$ and Y. W. Wang, RSC Adv., 2015, 5, 87484; $(g)$ J. Z. Gu, Y. H. Cui, X. X. Liang, J. Wu, D. Y. Lv and A. M. Kirillov, Cryst. Growth Des., 2016, 16, 4658; (h) J. Z. Gu, Y. H. Cui, J. Wu and A. M. Kirillov, $R S C A d v ., 2015$, $5,78889$.

6 G. M. Sheldrick, Program for Empirical Absorption Correction of Area Detector Data, University of Göttingen, Germany, 1996.

7 G. M. Sheldrick, SHELXTL Version 5.1, Bruker Analytical X-ray Instruments Inc., Madison, Wisconsin, USA, 1998.

8 (a) X. Y. He, B. C. Noll, A. Beatty, R. E. Mulvey and K. W. Henderson, J. Am. Chem. Soc., 2004, 126, 7444; (b) B. Chiari, A. Cinti, O. Crispu, F. Demartin, A. Pasini and O. Piovesana, J. Chem. Soc., Dalton Trans., 2002, 4672; (c) 
N. Srivastav, R. Mutneja, N. Singh, R. Singh, V. Kaur, J. Wagler and E. Kroke, Eur. J. Inorg. Chem., 2016, 1730; (d) D. M. Kuzyaev, D. L. Vorozhts, N. O. Druzhkov, M. A. Lopatin, E. V. Baranov, A. V. Cherkasov, G. K. Fukin, G. A. Abakumov and M. N. Bochkarev, J. Organomet. Chem., 2012, 698, 35; (e) C. P. Pradeep, S. Supriya, P. S. Zacharias and S. K. Das, Polyhedron, 2006, 25, 3588.

9 (a) E. Tynan, P. Jensen, N. R. Kelly, P. E. Kruger, A. C. Lees, B. Moubaraki and K. S. Murray, Dalton Trans., 2004, 3440; (b) S. J. Retting, R. C. Thompson, J. Trotter and S. Xia, Inorg. Chem., 1999, 38, 1360; (c) Q. Sun, A. L. Cheng, Y. Q. Wang, Y. Ma and E. Q. Gao, Inorg. Chem., 2011, 50, 8144.

10 (a) R. L. Rardin, P. Poganiuch, A. Bino, D. P. Goldberg, W. B. Tolman, S. C. Liu and S. J. Lippard, J. Am. Chem. Soc., 1992, 114, 5240; (b) R. A. Reynolds III, W. R. Dunham and D. Coucouvanis, Inorg. Chem., 1998, 37, 1232; (c) G. Fernndez, M. Corbella, J. Mahia and M. A. Maestro, Eur. J. Inorg. Chem., 2002, 2502; (d) S. Menage, S. E. Vitols, P. Bergerat, E. Codjovi, O. Kahn, J. J. Girerd, M. Guillot, X. Solans and T. Calvet, Inorg. Chem., 1991, 30, 2666; (e) H. Tian, Q. X. Jia, J. Y. Zhang and E. Q. Gao, Inorg. Chim. Acta, 2010, 363, 2481; (f) Q. H. Tan, Y. Q. Wang, H. T. Liu and Z. L. Liu, Inorg. Chem. Commun., 2015, 58, 67.

11 (a) B. Liu, R. Q. Zou, R. Q. Zhong, S. Han, H. Shioyama, T. Yamada, G. Maruta, S. Takeda and Q. Xu, Microporous Mesoporous Mater., 2008, 111, 470.

12 (a) M. Dai, X.-R. Su, X. Wang, B. Wu, Z.-G. Ren, X. Zhou and J.-P. Lang, Cryst. Growth Des., 2014, 14, 240; (b) Y. Shen, C. C. Fan, Y. Z. Wei, J. Hu, H. B. Zhu and Y. Zhao, Cryst. Growth Des., 2016, 16, 5859; (c) L. Liu, C. Huang, Z. Wang, D. Wu, H. Hou and Y. Fan, CrystEngComm, 2013, 15, 7095; (d) X.-W. Wang, J.-Z. Chen and J.-H. Liu, Cryst. Growth Des., 2007, 7, 1227; (e) X. He, C.-Z. Lu and D.-Q. Yuan, Inorg. Chem., 2006, 45, 5760; $(f)$ Y.-Z. Tang, G.-X. Wang, Q. Ye, R.-G. Xiong and R.-X. Yuan, Cryst. Growth Des., 2007, 7, 2382; (g) K. C. Wang, T. L. Liu, Y. J. Liu, X. Tian, J. Sun and Q. H. Zhang, CrystEngComm, 2016, 18, 8301.
13 (a) A. Niu, J. Yang, J. Guo, W. Q. Kan, S. Y. Song, P. Du and J. F. Ma, Cryst. Growth Des., 2012, 12, 2397; (b) L. Wen, Z. Lu, J. Lin, Z. Tian, H. Zhu and Q. Meng, Cryst. Growth Des., 2007, 7, 93; (c) X. X. Wang, X. Q. Wang, X. Y. Niu and T. P. Hu, CrystEngComm, 2016, 18, 7471.

14 (a) L. Wen, Y. Li, Z. Lu, J. Lin, C. Duan and Q. Meng, Cryst. Growth Des., 2006, 6, 530; (b) L. P. Zhang, J. F. Ma, J. Yang, Y. Y. Pang and J. C. Ma, Inorg. Chem., 2010, 49, 1535.

15 (a) D. M. Chen, X. Z. Ma, W. Shi and P. Cheng, Cryst. Growth Des., 2015, 15, 3999; (b) S. L. Wang, F. L. Hu, J. Y. Zhou, Y. Zhou, Q. Huang and J. P. Lang, Cryst. Growth Des., 2015, 15, 4087.

16 (a) R. L. Carlin, Magnetochemistry, Springer-Verlag, Berlin, Heidelberg, 1986; (b) O. Kahn, MolecularMagnetism, VCH, New York, 1993; (c) F. Lloret, M. Julve, J. Cano, R. RuizGarcía and E. Pardo, Inorg. Chim. Acta, 2008, 361, 3432 and references therein.

17 F. Lloret, M. Julve, J. Cano, R. Ruiz-Garcia and E. Pardo, Inorg. Chim. Acta, 2008, 361, 3432.

18 H. Tian, A. L. Cheng and E. Q. Gao, Dalton Trans., 2016, 45, 18696.

19 O. Kahn, Molecular Magnetism, Wiley-VCH, Weinheim, 1993. 20 (a) A. Rodríguez-Fortea, P. Alemany, S. Alvarez and E. Ruiz, Chem.-Eur. J., 2001, 7, 627; (b) J. Y. Zhang, Y. Ma, A. L. Cheng, Q. Yue, Q. Sun and E. Q. Gao, Dalton Trans., 2011, 40, 7219.

21 (a) J. M. Rueff, N. Masciocchi, P. Rabu, A. Sironi and A. Skoulios, Chem.-Eur. J., 2002, 8, 1813; (b) J. M. Rueff, N. Masciocchi, P. Rabu, A. Sironi and A. Skoulios, Eur. J. Inorg. Chem., 2001, 11, 2843.

22 Y. Q. Wang, K. Wang, Q. Sun, H. Tian, E. Q. Gao and Y. Song, Dalton Trans., 2009, 9854.

23 (a) C. J. Milios, T. C. Stamatatos, P. Kyritsis, A. Terzis, C. P. Raptopoulou, R. Vicente, A. Escuer and S. P. Perlepes, Eur. J. Inorg. Chem., 2004, 2885; (b) A. Escuer, B. Cordero, X. Solans, M. Font-Bardia and T. Calvet, Eur. J. Inorg. Chem., 2008, 5082; (c) V. Gomez and M. Corbella, Eur. J. Inorg. Chem., 2009, 4471. 